\title{
DIET AND LIFESTYLE GUIDELINES AND DESIRABLE LEVELS OF RISK FACTORS AND PROTECTIVE FACTORS FOR PREVENTION OF DEMENTIA: A SCIENTIFIC STATE- MENT FROM JOINT SYMPOSIUM OF JAAS AND APCNS
}

\author{
Ram B Singh ${ }^{1}$, Shaw Watanabe*2, Duo Li ${ }^{3}$, Teiji Nakamura4, Lekh Raj Juneja ${ }^{5}$, Toru Takahashi', \\ Anuj Maheshwari ${ }^{7}$, Narsingh Verma ${ }^{8}$, Sanit Wichansawakun ${ }^{9}$, Germaine Cornelissen ${ }^{10}$, Agnieszka \\ Wilczynska ${ }^{11}$, Ibrahim Jantan ${ }^{12}$, Ahmad Sulaeman ${ }^{13}$, Hardinsyah Ridwan ${ }^{14}$, Wan Abdul Manan WM ${ }^{15}$, \\ Viliam Mojto $^{16}$, Kumar Kartikey ${ }^{17}$ \\ ${ }^{1}$ Halberg Hospital and Research Institute, Moradabad, India
}

${ }^{2}$ Clinical \& Functional Nutriology, Life Science Promoting Association, Japan

${ }^{3}$ Institute of Nutrition \& Health, Qingdao University, Qingdao, China

${ }^{4}$ Kanagawa University of Human Services

${ }^{5}$ Lekb Raj Juneja, Rohto Pharmaceutical Co., Ltd. Osaka, Japan

${ }^{6}$ Toru Takahashi, Graduate School of Human Environmental Medicine, Fukuoka, Japan

${ }^{7}$ Anuj Maheshwari, CODS, BBD University, Lucknow, India

${ }^{8}$ Narsingh Verma, KG Medical University, Lucknow, India

${ }^{9}$ Sanit Wichansawakun (7) Department of Internal Medicine, Faculty of Medicine, Thammasat University, Thailand

${ }^{10}$ Germaine Cornelissen, Halberg Chronobiology Center, University of Minnesota Medical School, Minneapolis, Minn, USA

${ }^{11}$ Agnieszka Wilczynska (Poland), The Tsim Tsoum Institute, Krakow, Poland

${ }^{12}$ Ibrahim Jantan, (Faculty of Health and Medical Sciences, Taylor's University, Lakeside Campus, Selangor,Malaysia)

${ }^{13}$ Ahmad Sulaeman, (Indonesia), Department of Community Nutrition, Faculty of Human Ecology, Bogor Agricultural University,

Bogor, Indonesia

${ }^{14}$ Hardinsyah Ridwan, (Indonesia)

${ }^{15}$ Wan Abdul Manan WM, Healthy Eating and Lifestyle Practice (HELP), Kota Bharu, Malaysia

${ }^{16}$ Viliam Mojto, $3^{\text {rd }}$ Internal Clinic, Faculty of Medicine, Comenius University, Bratislava, Slovakia

${ }^{17}$ Kumar Kartikey, Halberg Hospital and research Institute, Moradabad, India

*Corresponding author: Shaw Watanabe, Clinical \& Functional Nutriology, Life Science, Japan

\section{ARTICLE INFO}

Received: 幽 April 15, 2019

Published: 幽 April 25, 2019

Citation: Ram B Singh, Shaw Watanabe, Duo Li, Teiji Nakamura, Lekb Raj Juneja, et al., Diet and Lifestyle Guidelines and Desirable Levels of Risk Factors

\section{ABSTRACT}

World Health Organization $\{\mathrm{WHO}$ ) estimate that the number of people living with dementia worldwide, may be approximately 50 million which is projected to increase to 75 million by 2030 . Epidemiological studies indicate a consistent relationship between the development of cognitive impairment and dementia with lifestyle-related risk factors, such as physical inactivity, unhealthy diets, short sleep, night shift work, tobacco use, and harmful use of alcohol. Apart from behavioural risk factors, cardiometabolic diseases (CMDs); obesity, hypertension, diabetes, stroke and hypercholesterolemia, as well as depression are also associated with an increased risk of dementia. In a few studies, social 
and Protective Factors for Prevention of Dementia: A Scientific Statement from Joint Symposium of JAAS and APCNS. Biomed J Sci \& Tech Res 17(3)-2019. BJSTR. MS.ID.003006.

Keywords: Western Diet; Risk Factors; Protective Factors; Japanese Diets; Indo Mediterranean Style Diets isolation and cognitive inactivity have been reported to be associated with dementia. The risk of dementia can also increase due to lack of protective health behaviors such as optimal sleep, moderate physical activity, Mediterranean style diets, caloric restriction or intermittent fasting, circadian restricted eating, supplementation of cocoa and probiotics, yoga therapy and moderation in alcohol intake. These health behaviors may also prevent biological risk factors of dementia; obesity, hypertension, hypercholesterolemia, stroke, diabetes and depression. It is possible that prevention of dementia is possible through modification of risk factors via implementation of key interventions that delay or slow cognitive decline or dementia. Some of the interventions may be optimal use of protective factors mentioned above; in the management of dementia.

\section{Introduction}

Dementia is not a normal part of ageing, although its common among elderly subjects [1]. It appears to be a syndrome, characterized with a chronic or progressive nature, caused by a variety of brain diseases that influence memory function, behavior, though process and ability to perform routine activities [1,2]. World Health Organization $\{\mathrm{WHO}$ ) estimate that the number of people living with dementia worldwide, may be approximately 50 million which is projected to increase to 75 million by 2030 . The number of cases of dementia are estimated to almost triple by 2050.In the Asia Pacific Region, the number of people with dementia will increase from 23 million in 2015 to almost 71 million by 2050. It means that by 2050 , more than half of the people with dementia worldwide (135 million) will live in this region [3-6]. Dementia is now the $7^{\text {th }}$ leading cause of death. In 2015, dementia affected roughly $5 \%$ of the world's elderly population, above the age of 60 years. Since the population is ageing, the number of people living with dementia would grow, and this figure is projected to continue to rise, especially in low and middle-income countries [1-4]. Dementia is a major cause of disability and dependency among older people worldwide, having a significant impact not only on individuals but also on careers, families, communities and societies $[1,2]$. The majority of care of dementia is provided by family careers. Several studies have shown a relationship between the development of cognitive impairment and dementia with lifestyle-related risk factors, such as physical inactivity, tobacco use, unhealthy diets, and harmful use of alcohol [5-10]. A great majority of cardiometabolic diseases (CMDs); obesity, hypertension, diabetes, hypercholesterolemia, obesity and depression are associated with an increased risk of developing dementia [5-11]. Apart from these risk factors, other potentially modifiable risk factors may be social isolation and cognitive inactivity. It is possible that prevention of dementia is possible through prevention and modification of risk factors via implementation of key interventions that delay or slow cognitive decline or dementia. The risk of dementia can also increase due to lack of protective health behaviors [11]. Since in Japan, the life expectancy is highest in the world, dementia is more rapidly increasing, compared to other countries, due to nutritional transition and alteration in other environmental risk factors [79,12-15]. This selected review aims to develop diet and lifestyle guidelines for prevention of dementia for Asians.

\section{Prevalence and Risk Factors of Dementia in Asians}

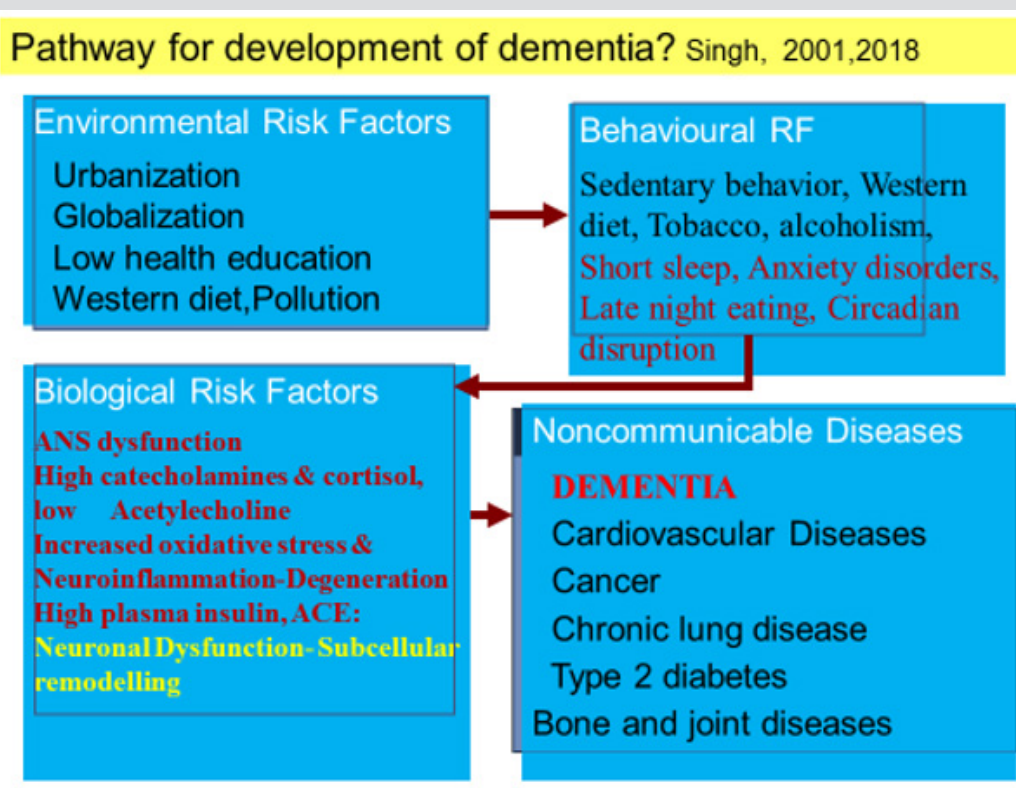

Figure 1: Pathways for development of memory dysfunction and dementia.

The exact prevalence of memory dysfunction or dementia in Asians, including Japan as well as the changes in the prevalence are not well known. In a systemic review, 21 studies were selected from 782 references [12]. The criteria for the clinical diagnosis of dementia were made based on the guidelines of the Diagnostic and Statistical Manual of Mental Disorders (DSM) in a majority of the 
studies. The prevalence of all types of dementia including memory dysfunction ranged from 2.9 to $12.5 \%$ which has been gradually progressive over the past few years. These findings indicate that the prevalence of dementia is increasing and has become a public health problem [12]. The burden of dementia in Japan is large and it is rapidly increasing with changes in diet and lifestyle and ageing of the population [14]. It is estimated that one in five elderly people will have dementia in Japan by 2025 and the most common form of dementia may be Alzheimer's disease (AD), accounting for around two-thirds of the patients with dementia. In this systematic review, the aim was to examine the epidemiology and associated burden of AD in Japan and to identify how $\mathrm{AD}$ is diagnosed and treated [14]. This national survey conducted in six regions of Japan reported the mean prevalence of dementia in people aged $\geq 65$ years to be $15.75 \%$ (95\% CI: $12.4,22.2 \%$ ), which is much higher than the previous estimated rate of $10 \%$ in 2010 [14]. The findings showed that $\mathrm{AD}$ was the predominant type of dementia, accounting for $65.8 \%$ of all cases. The risk factors of dementia were not duly studied in this survey, because the authors found that advancing age and low education were the only consistently reported risk factors [14]. The prevalence of Alzheimer's disease (AD) and dementia in Japan and developing countries like China and India have increased rapidly in recent years due to rapid increase in industrialization and urbanization with rapid changes in diet and lifestyle (Figure 1). The Hisayama Study reported that short sleep duration of less than 5 hours or more than 10 hours can also predispose dementia [16]. Five cross-sectional surveys of dementia were conducted among residents of a Japanese community, aged $\geq 65$ years to find out secular trends in the prevalence, incidence, and survival rate of dementia in a Japanese elderly population in a comprehensive manner [13]. The investigators also established 2 cohorts consisting of the residents of this age group without dementia in $1988(\mathrm{n}=803)$ and $2002(\mathrm{n}=1,231)$, and each was followed for 10 years. The age-standardized prevalence of all-cause dementia and Alzheimer disease (AD) increased with time (for allcause dementia: $6.8 \%$ in $1985,4.6 \%$ in $1992,5.3 \%$ in $1998,8.4 \%$ in 2005 , and $11.3 \%$ in 2012 , p for trend $<0.01$; for AD: $1.5 \%, 1.4 \%$, $2.4 \%, 3.9 \%$, and $7.2 \%$, respectively, $\mathrm{p}$ for trend $<0.01$ ). There was no secular change observed for vascular dementia (VaD) $(2.4 \%$, $1.6 \%, 1.5 \%, 2.4 \%$, and $2.4 \%$, respectively, $\mathrm{p}$ for trend $=0.59$ ).

The age- and sex-adjusted incidence of all-cause dementia and $\mathrm{AD}$, but not vascular dementia, increased from the 1988 cohort to the 2002 cohort (for all-cause dementia: adjusted hazard ratio [aHR] 1.68, 95\% confidence interval [CI] 1.38-2.06; for AD: a HR 2.07, 95\% CI 1.59-2.70; for VaD: a HR 1.18, 95\% CI 0.83-1.69). The 5 -year survival rate of all-cause dementia and AD improved from the 1988 cohort to the 2002 cohort (for all-cause dementia: $47.3 \%$ to $65.2 \%$; for $\mathrm{AD}: 50.7 \%$ to $75.1 \%$; all $\mathrm{p}<0.01$ ). It is possible that the increased incidence and improved survival rate of $\mathrm{AD}$ could have resulted in the steep increase in $\mathrm{AD}$ prevalence in the Japanese elderly.

The prevalence of dementia is lower among other Asian countries with lower life expectancy, compared to Japan and Western countries with greater life expectancy such as UK [36,15]. The overall prevalence of dementia in India, among 2002 subjects aged 25 years and above was significantly more common among men compared to women (total $=2.95 \%, n=59),(18.9 \%$ vs $1.0 \% ; \mathrm{P}<0.01 ; \mathrm{n}=38$ vs 21 ), respectively [15]. The risk of memory dysfunction or dementia overall showed a graded increase with age from 25 to 84 years in both sexes and the trends were significant, $\mathrm{P}<0.02$ ) for both genders. The prevalence of memory dysfunction $(1.8 \%)$ and dementia (1.05\%) were substantial as per screening made by Singh's Memory Function Rating Scale [15].

\section{Risk Factors and Protective Factors of Dementia}

There is limited epidemiological evidence that interventions targeting built environmental factors may encourage elderly subjects to engage in favorable behaviors to decrease the risk of dementia risk [10-18]. The increase in risk of dementia and AD in these countries, may be due to multiple associated factors such as the Western diet, sedentary behavior, obesity, alcohol and tobacco consumption and ageing of populations in conjunction with a lack of protective factors (Table 1). In a study from India, low cognitive activity, sedentary behavior, tobacco intake, Western diet, diabetes and CVD were independent risk factors of dementia [15]. Low education was not associated with risk. Of 59 (2.95\%) subjects having cognitive deficit or dementia, only $2(0.10 \%)$ had Alzheimer's disease (MRI), 21(1.05\%) dementia and 36(1.80\%) memory dysfunction. It seems that the lower prevalence of dementia and cognitive decline among Indians compared to developed countries, may be due to lower survival rate after the age of 55 years $(n=196,9.8 \%)$ and lower prevalence of subjects eating Western type diet and sedentary behavior, most likely due to physically demanding occupations. There was an increased prevalence of risk factors; Western type of foods; (refined, fried rapidly absorbed fast foods rich in trans and saturated fat, red and preserved meat and sugar) and tobacco intake and sedentary behavior among patients of cognitive deficit [15]. Yoga therapy including meditation, yoga postures, yoga breathing $(\mathrm{n}=221,10.26 \%)$; prayer $(\mathrm{n}=1215,56.4 \%)$ physical activity $(n=232,10.8 \%)$, Indo-Mediterranean style diet $(n=501,23.3 \%)$, time restricted eating at evening $(n=55,2.55 \%)$ were the protective factors. Apart from obesity, diabetes and CVD were also quite common risk factors among these subjects [18]. Multivariate logistic regression analysis revealed that yoga therapy, active prayer, physical activity, restricted eating at evening and Indo-Mediterranean diet were significantly inversely associated with dementia. It is possible that decreased intake of Western type foods, prevention of sedentary behavior and tobacco can protect against dementia among Indians. Further analysis and long term follow up, is needed to find out, the role of Eight Fold Path; Right Understanding, Intent, Speech, Action, Livelihood, Effort, Mindfulness, and Right Concentration as factor associated with dementia.

Table 1: Risk factors and protective factors of dementia.

\begin{tabular}{|c|c|c|}
\hline Risk Factors & Risky Behaviours & Protective Factors \\
\hline $\begin{array}{c}\text { Obesity and central } \\
\text { obesity }\end{array}$ & Short sleep & Physical activity \\
\hline Hypertension & Tobacco & $\begin{array}{c}\text { Mediterranean type } \\
\text { diet }\end{array}$ \\
\hline Diabetes mellitus & Alcoholism & Meditation and Prayer \\
\hline Hyperlipidaemia & Depression & Yoga postures \\
\hline
\end{tabular}




\begin{tabular}{|c|c|c|}
\hline Stroke & Sedentary behaviour & Intermittent fasting. \\
\hline $\begin{array}{c}\text { Coronary artery } \\
\text { disease }\end{array}$ & Low cognitive work & $\begin{array}{c}\text { Circadian restricted } \\
\text { energy intake }\end{array}$ \\
\hline Low education & & Low caloric diet. \\
\hline Pollution & & Music \\
\hline Age & & Intellectual work \\
\hline
\end{tabular}

The Japan Gerontological Evaluation Study, a population-based cohort study of subjects aged $\geq 65$ years, examined the association of neighborhood food environment with incidence of dementia. After a follow up of 3 years, dementia incidence for 49,511 participants was assessed through the public long-term care insurance system. During a follow up of 3 years, a total of 3,162 cases of dementia occurred. Compared with the highest quartile for objective availability of food stores, the hazard ratio adjusting for age and sex was $1.60(95 \% \mathrm{CI}=1.43,1.78)$ for the second-lowest quartile. Compared with the highest subjective availability of food stores, the hazard ratio was $1.74(95 \% \mathrm{CI}=1.49,2.04)$ for the lowest category. After successive adjustment for sociodemographic characteristics, health status, and other geographic neighborhood factors (availability of restaurants, convenience stores, and community centers), the hazard ratio remained statistically significant. It is possible that a lower availability of healthy food stores, was associated with greater incidence of dementia.

\section{Diet as Risk Factor and Protective Factor for Dementia}

Epidemiological studies indicate that Western type diet is a risk factor of dementia, whereas Mediterranean style diets may be protective factor against dementia [6,15,19-21]. Accumulating evidence suggests that higher Mediterranean diet adherence is associated with higher global cognitive performance and brain structural integrity as well as decreased risk of Alzheimer disease (AD) and vascular dementia (Figure 2). It is possible that dietary transition might explain the rising trend in the prevalence of dementia in Japan and in developing countries [6,19-21]. This study used two approaches to see whether dietary or other changes could explain AD trends in Japan and developing countries. One approach involved comparing trends of $\mathrm{AD}$ in Japan with changes in national dietary supply factors, alcohol consumption, and lung cancer mortality rates from zero to 25 years before the prevalence data. In the second approach The prevalence of $\mathrm{AD}$ for eight developing countries was compared with dietary supply factors from zero to 25 years before the prevalence data [6].The findings revealed that for Japan, alcohol consumption, animal product, meat and rice supply, and lung cancer rates correlated highly with prevalence of $\mathrm{AD}$, with the strongest correlation for a lag of 15-25 years. The findings in the eight-country study showed that total energy and animal fat correlated highly with prevalence of $\mathrm{AD}$, with a lag of 15-20 years. The possible mechanisms to explain the findings include increased obesity for the eight countries, and increases in cholesterol, saturated fat, and iron due to higher intake of animal products and meat for Japan. It is possible that prevalence of $\mathrm{AD}$ will continue rising in non-Western countries for some time unless we address major risk factors as well as behavioural risk factors; diet, obesity, alcoholism and smoking. The role of dietary patterns and their potential association with risk of incident dementia was examined in a general Japanese population comprising of 1006 community-dwelling Japanese subjects without dementia, aged 60-79 years [19]. All the subjects were followed up for a median of 15 years.

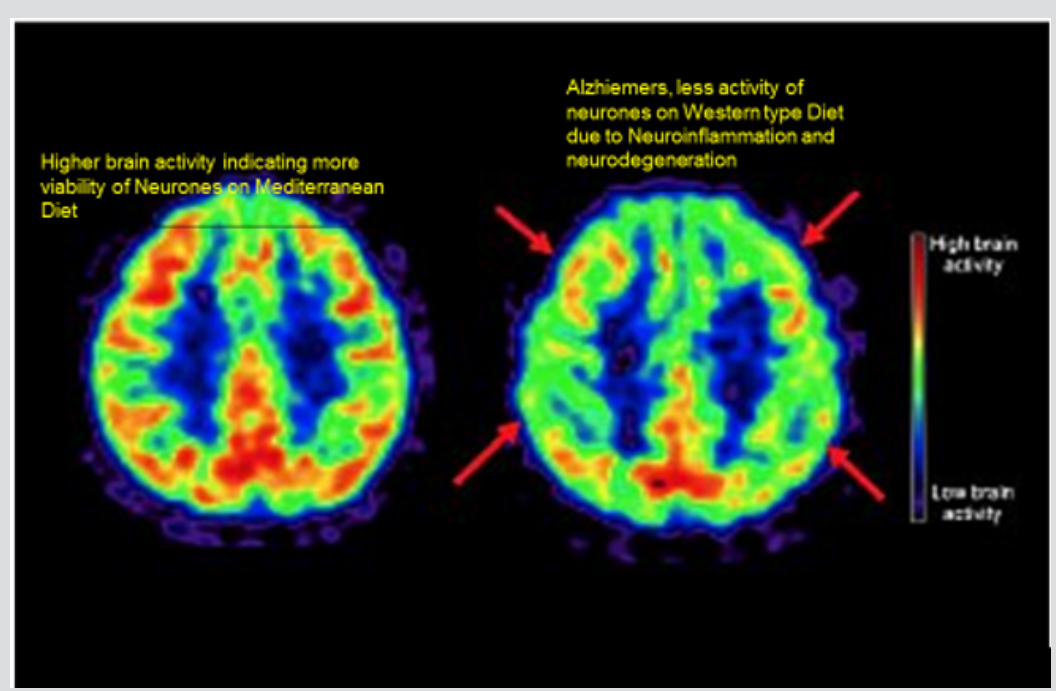

Figure 2: Effects of Mediterranean style diet and Western style diet on brain structure via magnetic resonance imaging.

In the results, seven dietary patterns were extracted; of these, dietary pattern 1 was correlated with high intakes of soybeans and soybean products, vegetables, algae, and milk and dairy products and a low intake of rice. During the follow-up, period of 15 years, 271 subjects developed all-cause dementia. Of these 271 subjects, 144 subjects had Alzheimer disease (AD), and 88 subjects had vascular dementia (VaD) [19]. After adjustment for potential confounders, risks of development of all-cause dementia, $\mathrm{AD}$, and vascular dementia were reduced by 0.66 (95\% CI: 0.46, 0.95), 0.65 (95\% CI: 0.40, 1.06), and 0.45 (95\% CI: 0.22, 0.91), respectively, in subjects in the highest quartile of score for dietary pattern 1 compared with subjects in the lowest quartile. It is possible that a higher adherence to a dietary pattern characterized by a high intake of soybeans and soybean products, vegetables, algae, and milk and dairy products and a low intake of rice is associated with reduced risk of dementia [19]. In a cohort of non-demented, non- 
depressed older adults including community-dwelling subjects (n = 82; aged $\sim 68.8$ y; $50 \%$ female, $50 \%$ minority) underwent food frequency assessment and neuropsychological assessments along with neuroimaging [20]. The scores for Mediterranean style diets were quantified with the use of published criteria, and participants were divided into high and low (median split) adherence groups. The results revealed that compared with the low Mediterranean diet group, the high Mediterranean style diet group was associated with better learning and memory performance and larger dentate gyri via neuroimaging. Mediterranean diet adherence was not associated with information processing, executive functioning. It is possible that the association between increasing adherence to Mediterranean style diets and specific cognitive and neuroimaging phenotypes and that, altered diets, may be associated with AD [20].

Although it has been observed that the Japanese dietary pattern has a preventive effect against incident dementia, there is little evidence investigating this issue [19-21]. The present prospective cohort study investigated the association between dietary patterns and incident dementia among 14,402 elderly Japanese subjects ( $\geq 65$ years) participating in a community-based, prospective cohort study [21]. Three dietary patterns (Japanese pattern, animal food pattern, and high-dairy pattern) were derived using principal component analysis of the consumption of 39 food and beverage items assessed using a food frequency questionnaire. The incidence of dementia was $9.0 \%$ with 71,043 person-years of follow-up. The score for the Japanese dietary pattern was associated with a lower risk of incident dementia (hazard ratio of the highest quartile vs the lowest, 0.80 ; 95\% confidence interval: 0.66-0.97; p-trend = .016). The animal food pattern and the high-dairy pattern showed no significant association with incident dementia. This study confirmed that the Japanese dietary pattern was associated with a decreased risk of incident dementia [21]. It is clear from above studies that increased intake of alcohol, animal products, meat and white rice as well as Western type foods; salt, sugar and saturated fat may be underlying dietary factors responsible for rising prevalence of dementia in Japan and other Asian countries. Modification of these diets by substituting medical rice and other whole grains for white rice in conjunction with Mediterranean foods; vegetables, fruits, fish, olive oil, and/or mustard oil may be protective against dementia [11,15-22]. These diets and moderate physical activity are also protective against CMDs and cancers and osteoporosis that are major causes of deaths and disability among elderly populations [1,2,22-28].

\section{Mediterranean Style Diets and Risk of Dementia}

Mediterranean style diets are rich in fruits, vegetables, whole grains, nuts, olive oil and fish with lower in refined foods, red meat and preserved meats [29-32]. These diets can lower the risk of cognitive decline by reducing the risk of developing CMDs, a known risk factor for dementia, as well as by their direct effect [32-37]. The mechanism of action of this diet is that it also has an anti-oxidant and anti-inflammatory effects that are major mechanisms underlying dementia [32]. There is strong evidence for protective effects of vitamin $\mathrm{E}, \mathrm{B}$ vitamins, magnesium, vitamin D, flavonoids, amino acids and n-3 fatty acids, and deleterious effects of sugary and rapidly absorbed refined fast foods, saturated and trans-fat, red and preserved meats on dementia $[29,31,38]$.
Intake of food pellets containing pre-germinated brown rice has been found to alleviate cognitive deficits caused by $\beta$-amyloid peptide25-35 in mice [38]. Among specific foods with evidence of neuroprotection are leafy and other vegetables, berries, whole grains (beans and pulses, porridge, grams, flex seeds, other seeds, soya beans and millets) and seafood [33-40]. The PREDIMED study, assessed 522 participants at high vascular risk (44.6\% men, age $74.6 \pm 5.7$ years at cognitive evaluation) enrolled in a multicenter, randomized, primary prevention trial [35]. After adjustment for sex, age, education, apolipoprotein E genotype, family history of cognitive impairment/dementia, smoking, physical activity, body mass index, hypertension, dyslipidaemia, diabetes, alcohol and total energy intake, participants allocated to the Med diet + EVOO showed higher mean mini mental state examination (MMSE) and clock drawing test (CDT) scores with significant differences versus control (adjusted differences: $+0.6295 \% \mathrm{CI}+0.18$ to +1.05 , $\mathrm{p}=0.005$ for MMSE, and $+0.5195 \% \mathrm{CI}+0.20$ to +0.82 , $\mathrm{p}=0.001$ for CDT) The adjusted means of MMSE and CDT scores were also higher for participants allocated to the Med diet + Nuts versus control (adjusted differences: +0.57 (95\% CI +0.11 to +1.03$)$, $\mathrm{p}=0.015$ for MMSE and $+0.33(95 \% \mathrm{CI}+0.003$ to +0.67$), \mathrm{p}=0.048$ for CDT). It is possible that an intervention with Med diets enhanced with either EVOO or nuts appears to improve cognition compared with a lowfat diet [35]. In a meta-analysis 32 studies from 25 unique cohorts, including 5 randomized, controlled trials and 27 observational studies, met the inclusion criteria [33].

The majority of studies showed that the Mediterranean style diet was associated with improved cognitive function, a decreased risk of cognitive impairment or decreased risk of dementia, or Alzeimers disease. Of the total, 3 studies reported no correlation between the diet and Alzheimer's disease, another 3 studies reported no association between the diet and cognitive impairment, and 5 studies found no association between the diet and cognitive function. In view of the large heterogeneity, differences in quality and the limitations in study design, it is possible that adherence to the Mediterranean style diet was associated with better cognitive performance [34]. In a more recent review, following PRISMA guidelines and was conducted using four databases and resulted in 31 articles of interest [36]. Cross-sectional studies and cohort studies in the non- Mediterranean region showed mixed results. However, cohort studies in the Mediterranean region and randomized controlled trials showed more cohesive outcomes of the beneficial effect of the Mediterranean style diets on cognitive function [36]. Although more standardized and in-depth studies are needed to strengthen the existing body of evidence, results from this review indicate that the Mediterranean diet may have a major role in cognitive health and risk of Alzheimer's disease and dementia. According to another review, several studies have examined dietary patterns, particularly the Mediterranean and DASH (Dietary Approaches to Stop Hypertension) diets. However, neither of these diets are tailored to the specific foods and nutrients that have been identified as neuroprotective [37]. A newly developed diet, called MIND (Mediterranean-DASH Intervention for Neurodegenerative Delay), incorporates many elements of the Mediterranean and DASH diets but with modifications that reflect the best evidence for neuronal protection [40]. 
These problems of the association of Mediterranean style diets with dementia may be explained by inadequate attention to nutrient/food intake in the interpretation of results of the study. In a further study, the German Study on Aging, Cognition and Dementia in Primary Care Patients (Age Code), dietary intake of red wine, white wine, coffee, green tea, olive oil, fresh fish, fruits and vegetables, red meat and sausages, was assessed by a singlefood-questionnaire [39,50]. Participants aged $75+$ of cohort $(n=2622)$ were regularly followed over 10 years for incidence of Alzheimer's disease $(n=418)$. The results showed that only higher red wine intake was associated with a lower incidence of Alzheimer's disease ( $\mathrm{HR}=0.92 ; \mathrm{P}=0.045)$. However, this was true only for men (HR $=0.82 ; \mathrm{P}<0.001$ ), while in women higher red wine intake was associated with a higher incidence of Alzheimer's disease $(H R=1.15 ; P=0.044)$, and higher white wine intake with a more pronounced memory decline over time $(\mathrm{HR}=-0.13$; $P=0.052)[39,50]$. It is clear that no evidence was observed for these single foods to be protective against cognitive decline, with the exception of red wine, which reduced the risk for Alzheimer's disease only in men. A recent review included 32 studies from 25 unique cohorts, including 5 randomized, controlled trials and 27 observational studies [56]. The majority of studies showed that the Mediterranean style diet was associated with improved cognitive function, a decreased risk of cognitive impairment or decreased risk of dementia. Three studies found no correlation between the diet, and cognitive impairment, and 5 studies found no association between the diet and cognitive function [41]. There are numerous studies to support that certain foods such as fish, olive oil, nuts, coffee, tea, wine etc. can inhibit memory dysfunction and dementia and the major benefit is achieved due to flavonoids, peptides, amino acids and omega- 3 fatty content of these foods [42-56].

\section{Effects of Flavonoids on Dementia}

It is possible that the most effective dietary ingredient responsible for beneficial effects of foods on dementia may be flavonoids which are also rich in whole grains such as Medical rice, legumes, millets, flex seeds, corn, etc. [38-40]. Flavonoids constitute a large group of polyphenolic compounds with numerous beneficial effects on behavior and cognition, which vary from learning and memory enhancement to an improvement of general cognition. Flavonoids have also been implicated in neuronal proliferation and survival, by acting on a variety of cellular signaling cascades, including the ERK/CREB/BDNF and PI3K/Akt pathway, reduction of oxidative stress and relief from clinical manifestations of Alzheimer's disease [36,39]. Electrophysiological aspect in brain, indicate that flavonoids can promote long term potentiation in the hippocampus, supporting the hypothesis of synaptic plasticity mediation indicating a neuroprotective effect of flavonoid compounds in the brain. It is possible that flavonoid content of Mediterranean foods could be a potential clinical direction for prevention and/or attenuation of cognitive decline deterioration which accompanies various brain disorders [39-48] \& (Table 1).

\section{Medical Rice as Whole Grain for Dementia}

Medical rice is rich in functional ingredients; dietary fibers, GABA, selenium and magnesium phenolic acids and flavonoids, anthocyanins, pro-anthocyanidins, tocopherols, tocotrienols, $\gamma$-oryzanol, and phytic acid that provide a good balance of the bacterial flora and of the immune system, if consumed as whole grains [38,57-60]. Experimental study by Mamiya 2013 suggested that continuous feeding of food pellets containing pre-germinated brown rice attenuates the Aß25-35-induced impairments of cognitive function, and inhibited increases in lipid peroxidation in the hippocampus related to cognition [38]. Whole grain is also an important ingredient of MIND diet (Mediterranean- DASH Intervention for Neurodegenerative Delay,2015), incorporates many elements of the above-mentioned diets for neuroprotection [40]. Catechin flavonoids rich in tea and cocoa can reduce cognitive decline and the levels of beta-amyloid in a mouse model of Alzheimer's disease. Improvement in cognitive function is not always accompanied by a change in pathological features, so it is not known whether flavonoids have a direct impact on beta-amyloid $[41,54,55]$. There is evidence that components of the germ layer and bran of Brown rice help maintain good health and prevent dementia [57-60]. Since the germ layer and bran absorb very less water and are very hard and difficult to cook, they are often removed during processing. To solve these problems, in this study, we tried to use a high-pressure technique to solubilize it. High pressure treatment increased the water absorbency of brown rice without nutrient loss. It also ameliorated cognitive dysfunction and reduced the levels of amyloid- $\beta$, which is a major protein responsible for Alzheimer's disease, in the brain. In this experiment the authors have analyzed the benefits of brown rice (BR, Oryza sativa L.) (Table 2) for the prevention of dementia and other dementias because it is widely cultivated and consumed in Asia and other regions. Brown rice is often processed to remove the germ layer and bran because they are very hard, difficult to cook, and poorly digested. Interestingly, these regions of rice contain many ingredients that can be used to prevent dementias.

Table 2: Frequency of depression and its characteristics in patients with acute coronary syndrome compared to healthy and controls Modified from reference [99]; ${ }^{*} \mathrm{P}<0.02,{ }^{* *} \mathrm{P}<0.001$.

\begin{tabular}{|c|c|c|}
\hline Symptom & $\begin{array}{c}\text { Acute coronary } \\
\text { syndrome (n=435) }\end{array}$ & $\begin{array}{c}\text { Control subjects } \\
\text { (n=495) }\end{array}$ \\
\hline $\begin{array}{c}\text { Depression (severe } \\
\text { and moderate) }\end{array}$ & $60(13.8)^{* *}$ & $15(3.0)$ \\
\hline Possible depression & $26(5.9)^{*}$ & $16(3.2)$ \\
\hline $\begin{array}{c}\text { Total of depression } \\
\text { subjects }\end{array}$ & $86(19.8)^{* *}$ & $31(6.3)$ \\
\hline $\begin{array}{c}\text { Anxiety; memory } \\
\text { dysfunction, fear, } \\
\text { weeping }\end{array}$ & $41(9.4)^{* *}$ & $17(3.9)$ \\
\hline $\begin{array}{c}\text { Excess of thinking and } \\
\text { difficulty in sleeping }\end{array}$ & $96(22.0)^{* *}$ & $52(10.5)$ \\
\hline $\begin{array}{c}\text { Depressed mood } \\
\text { without desire to get } \\
\text { up in the morning }\end{array}$ & $58(13.4)^{* *}$ & $24(4.8)$ \\
\hline $\begin{array}{c}\text { Depressed mood } \\
\text { without desire to do } \\
\text { routine work }\end{array}$ & $52(11.9)^{*}$ & $15(3.0)$ \\
\hline $\begin{array}{c}\text { Tingling and } \\
\text { heaviness in head }\end{array}$ & $62(12.2)^{* *}$ & $24(4.8)$ \\
\hline Agitation & $41(9.4)^{* *}$ & $10(2.0)$ \\
\hline
\end{tabular}




\begin{tabular}{|c|c|c|}
\hline $\begin{array}{c}\text { Known diabetes } \\
\text { mellitus (by records) }\end{array}$ & $105(24.1)^{* *}$ & $52(10.5)$ \\
\hline $\begin{array}{c}\text { Values are number } \\
(\%)\end{array}$ & & \\
\hline
\end{tabular}

Ferulic acid has antioxidant potential and it is neuroprotective effects and inhibits amyloid $\beta(A \beta)$ production and aggregation [32]. They also include vitamin B6, vitamin B12 and folic acid, which are essential for methionine metabolism; the deficiency of them leads to an increase in blood homocysteine levels, increasing the risk of vascular diseases and dementia. The levels of gamma-aminobutyric acid (GABA), which acts as an excitatory neurotrans- mitter in the brain and plays a crucial role in regulating nerve excitation, are reduced in the brains of patients with Alzeimers disease than in the brains of healthy adults [32]. The Indian Lifestyle and Heart study reported that the prevalence of cognitive decline and dementia was $2.95 \%(n=59)$ associated with diet score below 6 out of $1-10$, indicating increased intake of Western dietary pattern and lower Mediterranean diet pattern. There is potential epidemiological evidence of a strong correlation among diet, lifestyle factors and the onset and consolidation of dementia and Alzheimer's disease [28]. It has been demonstrated that dementia, diabetes, obesity, insulin resistance, and cardiovascular disease are strongly interconnected pathologies. Preventive strategies and nutritional interventions seem to be promising approaches to delay neurocognitive decline and reduce the risk of dementia and other non-psychiatric comorbidities. In this regard, healthy dietary patterns, characterized by high intake of plant-based foods, probiotics, antioxidants, soy beans, nuts, and omega- 3 polyunsaturated fatty acids, and a low intake of saturated fats, animal-derived proteins, and refined sugars, have been shown to decrease the risk of neurocognitive impairments and eventually the onset of dementia. In brief, the ageing population is accompanied by increased rates of cognitive decline and dementia, which have profound impact on an individual's health and quality of life, as well as on the life of their caregivers. the beneficial effects of Mediterranean diet are associated with overall diet composition, rather than single nutrient supplementations, for the prevention or the delay of Alzheimer's disease and dementia. The Mediterranean diet has been known to aid in reducing the risk of CVDs, cancer and diabetes. The highest beneficial components of Mediterranean style diets are vegetables and whole grains, because they are rich in polyphenolics and flavonoids. Medical rice is a whole grain which is rich in GABA, selenium and magnesium phenolic acids and flavonoids; anthocyanins, pro-anthocyanidins, tocopherols, tocotrienols, $\gamma$-oryzanol which have potential antioxidant effects [29]. Flavonoids have been recently linked to better cognitive function in the elderly population. However, it should be noted that the majority of findings come from epidemiologic studies that provide evidence for a correlation between the Mediterranean diets and cognition but not for a cause and effect relation. More controlled trials are required to establish a causational relation.

\section{Sedentary Behavior as Risk Factor of Dementia}

Apart from Western style diets, physical inactivity appears to be the second most important lifestyle factor for the increased risk of dementia [61-65]. However, moderate physical activity may be important lifestyle modification for prevention of dementia.
Moderate physical activity is also known to inhibit all the CMDs that are known to increase the risk of dementia. The modern lifestyles in industrialized and urbanized countries are characterized with prolonged sedentary activities, which may pose a risk to CMDs as well as neuropsychiatric disorders [61]. The English Longitudinal Study of Ageing, comprised of 6359 subjects, aged $64.9 \pm 9.1$ yrs., as a cohort of community dwelling older adults. At baseline television viewing time ( $\geq 6 \mathrm{hrs} / \mathrm{d}$ versus $<2 \mathrm{hrs}$. $/ \mathrm{d}$ ) was associated with higher depressive symptoms (coefficient $=0.49,95 \% \mathrm{CI}, 0.63-0.35$ ) and poorer global cognitive function $(-1.16,-1.00--1.31)$ [61]. However, subjects using the internet reported lower depressive symptoms $(-0.58,-0.50--0.66)$ and higher global cognitive function $(1.27,1.37$ - 1.18). There was no association between any sedentary behaviors at baseline and change in mental health measures over follow-up, suggesting that the difference in scores persisted but did not increase over time. In a systematic review of studies conducted on sedentary behavior at work and cognitive functioning, only a few studies showed that sedentary behavior was a risk factor of dementia [62]. However, total time in sedentary activities and presence of physical activity was not reported in most of the negative studies.

Since physical inactivity and CVDs are major risk factors of dementia, it is necessary to emphasize that physical activity can reverse dementia similar to its effects on CVDs [28]. A recent study among 5861 women (mean [SD] age, 78.5 [6.7] years),reported 143 CAD events and 570 CVD events [28]. The HRs for CAD in the highest vs lowest quartiles of light physical activity were 0.42 (95\% CI, 0.25-0.70; P for trend <.001) adjusted for age and race/ ethnicity and 0.58 (95\% CI, 0.34-0.99; P for trend $=.004$ ) after additional adjustment for education, current smoking, alcohol consumption, physical functioning, comorbidity, and self-rated health. Corresponding HRs for CVD in the highest vs lowest quartiles of light physical activity were 0.63 (95\% CI, 0.49-0.81; P for trend $<.001$ ) and 0.78 (95\% CI, 0.60-1.00; P for trend =.004). The HRs for a 1-hour/day increment in light activity after additional adjustment for MV physical activity were 0.86 (95\% CI, 0.73-1.00; P for trend $=.05)$ for CAD and 0.92 (95\% CI, 0.85-0.99; $\mathrm{P}$ for trend $=.03$ ) for CVD [28]. The results support the conclusion that all movement counts for the prevention of CAD and CVD in older women which may be similar for prevention of dementia. In a cross-sectional study, including community-dwelling dementia patients $(n=45$, age $79.6 \pm 5.9$ years, Mini-Mental State Examination [MMSE] $22.8 \pm$ 3.2) and matched controls ( $n=49$, age $80.0 \pm 7.7$ years, MMSE 29.0 \pm 1.2 ) were assessed [63]. In dementia patients, relative sedentary time and sedentary bout duration was significantly higher than in controls (median [interquartile range] 57\% [49-68] vs. 55\% [4759] and 18.3 [16.4-21.1] min vs. 16.6 [15.3-18.4] $\mathrm{min}, \mathrm{p}=0.042$ and $p=0.008$, respectively). These patients spent a lower percentage of their waking time in light-to-moderate and moderate-to-vigorous intensity physical activities $(20 \%$ [15-23] vs. 22\% [18-25] and 5\% [2-10] vs. $10 \%$ [5-13], $p=0.017$ and $p=0.001$, respectively) [63]. It is possible that dementia patients are more sedentary and perform less physical activity compared to cognitively healthy controls. A further study reported that elderly subjects spend a majority of time in sedentary behavior which may be linked to cognitive decline via glycemic control [64]. Interestingly, substituting sitting with 
intermittent light activity can improve glycemic control. However, there is a need to determine if light activity can forestall cognitive decline and engaging in more light activity may be an achievable public health target [64].

In a population-based study among 800 women, aged 38-54 years, subjects were followed from 1968 to 2012 [27]. Assessment of cognitive (artistic, intellectual, manual, religious, and club) and physical activity were made at baseline. The diagnosis of dementia $(n=194)$, Alzheimer disease $(n=102)$, vascular dementia $(n=$ 27), mixed dementia $(n=41)$, and dementia with cerebrovascular disease $(n=81)$ were made according to established criteria. The findings revealed that cognitive activity in midlife was associated with a decreased risk of total dementia (hazard ratio [HR] 0.66; 95\% confidence interval [CI] 0.49-0.89) and Alzheimer disease (HR 0.54; 95\% CI 0.36-0.82) during follow-up. Physical activity in midlife was associated with a reduced risk of mixed dementia (HR 0.43; 95\% CI 0.22-0.86) and dementia with cerebrovascular disease (HR 0.47; 95\% CI 0.28-0.78). The results were similar after excluding those who developed dementia before $1990(n=21)$, except that physical activity was then also associated with reduced risk of total dementia (HR 0.67; 95\% CI 0.46-0.99) [27]. It is possible that midlife cognitive and physical activities are independently associated with reduced risk of dementia and dementia subtypes. The results indicate that these midlife activities may have a role in preserving cognitive health in old age. In another systematic review ascertaining the contribution of sedentary behavior towards associated changes in cognitive function over the adult lifespan for $\geq 40$ years, follow up were included [65]. There were 8 studies which examined the association of sedentary behavior with cognitive function of which, 6 studies reported significant negative associations between sedentary behavior and cognitive function. Across all of the eight studies, 8 different measures of sedentary behavior and 13 different measures of cognitive function were used [65].

In view of worldwide increasing rate of all-cause dementia and the lack of effective drug therapy, it seems that the value of lifestyle approaches as prevention strategies is important. Since emerging evidence indicates that sedentary behavior is significantly associated with impaired cognitive function, a better understanding of this association would substantially add to our knowledge of how to promote healthy lifestyle in the population to prevent cognitive ageing. Sedentary behavior is associated with lower cognitive performance, although the attributable risk of sedentary time to all-cause dementia incidence is unclear. Our systematic review provides evidence that limiting sedentary time and concomitantly engaging in regular moderate-to-vigorous physical activity may best promote healthy cognitive ageing. In a meta-analysis, the effect of physical activity interventions on cognitive function in dementia patients, among 802 patients included,18 randomized control trials that applied a physical activity intervention with cognitive function as an outcome measure [66]. The primary analysis yielded a positive overall effect of physical activity interventions on cognitive function $(\operatorname{SMD}[95 \%$ confidence interval] $=0.42[0.23 ; 0.62]$, $\mathrm{p}<.01$ ).Physical activity interventions were equally beneficial in patients with Alzheimer's disease (AD, SMD $=0.38$ [0.09;0.66], $\mathrm{p}<$ .01 ) and in patients with AD or a non-AD dementia diagnosis (SMD $=0.47[0.14 ; 0.80], \mathrm{p}<.01)$ in the secondary analysis. After com- bining (i.e. aerobic and non-aerobic) exercise interventions (SMD $=0.59[0.32 ; 0.86], \mathrm{p}<.01)$ and aerobic-only exercise interventions $(\mathrm{SMD}=0.41[0.05 ; 0.76], \mathrm{p}<.05)$ there was a positive effect on cognition, while this association was absent for non-aerobic exercise interventions (SMD $=-0.10[-0.38 ; 0.19], p=.51)$. The interventions offered at both high frequency (SMD $=0.33[0.03 ; 0.63], \mathrm{p}<.05)$ and at low frequency $(\mathrm{SMD}=0.64[0.39 ; 0.89], \mathrm{p}<.01$ ) had a positive effect on cognitive function [66]. This meta-analysis suggests that physical activity interventions positively influence cognitive function in patients with dementia. This beneficial effect was independent of the clinical diagnosis and the frequency of the intervention and was driven by interventions that included aerobic exercise. However, the Dementia and physical activity (DAPA) trial of moderate to high intensity exercise training for people with dementia found no benefit of exercise in dementia indicating that other lifestyle factors should also be taken care of to get benefit from exercise [67]. Apart from dementia, both high sedentary time and long mean bout durations were associated in a dose-response manner with increased risk of CVD in older women, which suggests that efforts to reduce CVD burden might benefit from addressing either or both components of sedentary behavior [68]. Sedentary behavior is also known to enhance all-cause mortality [69]. Recently, it has been suggested that patients with subjective cognitive decline should be identified as a useful population to look for preclinical Alzheimer's disease [70]. Diet and lifestyle modifications among such patients showing moderately positive results in non-demented elderly patients and moderately positive interim results for lowering amyloid in pre-dementia Alzheimer's disease are quite interesting [70]. The findings indicate that, ultimately, there will be a future in which specific anti-Alzheimer's therapy may be combined with lifestyle modifications targeting neuronal health to jointly inhibit the disease.

\section{Behavioral Risk Factors and Dementia}

The prevalence of dementia continues to increase worldwide, although incidence in the western world may have declined on account of better management of CVDs and improvement in diet and lifestyle, at least among higher social classes, leading to improvement in neuronal health [70]. The definition of Alzheimer's disease, the most prevalent cause of dementia, continue to be defined by the combined presence of amyloid and tau, although many investigators are gradually moving away from the simple assumption indicating that age-related, protective, and diseasepromoting factors probably interact with the core mechanisms of the disease. Interestingly, amyloid $\beta 42$, and tau proteins remain the established core cerebrospinal biomarkers; novel candidate biomarkers include amyloid $\beta$ oligomers and synaptic markers [70]. These markers should be targeted by modification of behavioural risk factors for prevention of dementia. Epidemiological studies indicate that apart from sedentary behavior and diet, different behaviors such as eating habits, eating and sleeping late at night, depression, type-A behavior, insomnia, night shift work and circadian disruption of sleep, have been reported to predispose to CVDs, T2DM and other NCDs [23-29,71-75]. Therefore, behavioral modulations appear to be most important factors in the pathogenesis and prevention of cardio-metabolic diseases (CMDs) because it may also inhibit dementia. Association of night eating habits with metabolic syndrome and its components has been 
reported in a longitudinal study [71]. This is important because obesity and CVDs are risk factors of dementia.

It has been shown that caloric restriction (CR) delays aging and possibly delays the development of Alzheimer's disease (AD) [72-74]. The mechanism may involve interoceptive cues, as well as reduced energy intake per se, which act by influencing central circadian clock and peripheral clocks regulating metabolism. The study showed that hunger alone, induced by a ghrelin agonist, reduced $\mathrm{AD}$ pathogenesis and improved cognition in the APPSwDI mouse model of AD. Both treatments also reduced levels of amyloid beta $(A \beta)$ and inflammation (microglial activation) at 6 months of age compared to the control group, similar to the effect of caloric restriction [72]. It seems that, a hunger-inducing drug attenuates pathogenesis of $\mathrm{AD}$, in the absence of caloric restriction, and the neuroendocrine aspects of hunger also prevent age-related cognitive decline $[73,74]$. The vulnerability of the neuronal health to increase in age is all too often manifest in neurodegenerative disorders such as AD and Parkinson's diseases. In this review of literature, we describe evidence indicating that two dietary interventions, caloric restriction (CR) and intermittent fasting (IF), can prolong the health-span of the nervous system by impinging upon fundamental metabolic and cellular signaling pathways that regulate life-span. Restriction of calories and intermittent fasting influence energy and oxygen radical metabolism, and cellular stress response systems, in ways that protect neurons against genetic and environmental factors to which they would otherwise succumb during aging [72-74]. There are multiple interactive pathways and molecular mechanisms by which these two methods benefit neurons including those involving insulin-like signaling; FoxO transcription factors, sirtuins and peroxisome proliferator-activated receptors. It is possible that these pathways stimulate the production of protein chaperones, neurotrophic factors and antioxidant enzymes, that are protective to neurons to inhibit the stress and resist disease. A better understanding of the impact of these agents on the aging of neurons will likely lead to novel approaches for preventing and treating neurodegenerative disorders.

Intermittent fasting appears to be an effective dietary intervention to counteract the associated metabolic abnormalities with CMD [75]. It has been proposed that browning of white adipose tissue (WAT) is the main underlying mechanism for the occurrence of fasting -mediated metabolic benefits. It remains unclear whether fasting can retain its efficacy in different models, such as genetically obese/diabetic animals. In one experiment, leptin-deficient ob/ob mice were subjected to 16 weeks of isocaloric intermittent fasting, and comprehensive metabolic phenotyping was conducted to assess the metabolic effects of fasting intermittently. Interestingly, isocaloric intermittent fasting-subjected ob/ob animals failed to exhibit reduced body weight gain, lower fat mass, or decreased liver lipid accumulation. Intermittent fasting with isocaloric diet showed no effects on thermogenesis nor induce browning of white adipose tissue in ob/ob mice. Despite the lack of improvement in insulin sensitivity, isocaloric diet on intermittent fasting, in ob./ob animals resulted in improvement in glucose tolerance as well as higher postprandial insulin level, with elevated incretin expression, indicating that intermittent fasting with isocaloric diet is effective in improving nutrient-stimulated release of insulin which complimentary for all the CMDs [75]. During the process of ageing, there is accumulation of dysfunctional and damaged cellular proteins and organelles, resulting in a disruption of cellular homeostasis and progressive degeneration which increases the risk of cell death. Interestingly, physical activity and caloric restriction are known to promote healthy ageing and mitigate age-related pathologies that can modulate the proteome possibly by influencing intracellular protein quality [76]. It is known that autophagy is an evolutionary conserved recycling pathway responsible for the degradation, then turnover of cellular proteins and organelles which may be linked to the aging process. The target of rapamycin complex 1 (TORC1), a central kinase involved in protein translation, is a negative regulator of autophagy, and inhibition of TORC1 enhances lifespan which can decrease the production of cellular proteins that may otherwise enhance the deleterious accumulation observed in aging. TORC1 may also exert its effects in an autophagydependent manner. Caloric restriction and exercise may cause a concomitant downregulation of TORC1 activity and upregulation of autophagy in a number of tissues. Moreover, exercise-induced TORC1 and autophagy signaling share common pathways with that of restriction of calories. It is possible that the longevity effects of exercise and restriction of calorie may stem from the maintenance of the proteome by balancing the synthesis and recycling of intracellular proteins and thus may represent practical means to promote longevity $[75,76]$.

\section{Sleep Disorders, Sleep Behavior and Dementia}

Apart nutritional factors and short sleep, disturbances in sleep such as insomnia, night shift work and circadian disturbances of sleep, may also predispose memory dysfunction [77-79]. A casecontrol study involved 51,734 patients, a subset of Taiwan's National Health Insurance Research Database of reimbursement claims, diagnosed with primary insomnia as the test group and 258,715 non-primary insomnia participants aged 20 years or older as the reference group [77]. Cox proportion hazards model revealed that the cohort with primary insomnia revealed a higher prevalence of diabetes, dyslipidemia, hypertension, coronary artery disease, chronic liver disease, and chronic kidney disease at baseline. After adjustment of these diseases, primary insomnia remained a significant predisposing factor for developing dementia and was associated with a 2.14-fold (95\% confidence interval, 2.01-2.29) increase in the risk of dementia. It is possible that patients with primary insomnia, especially those under 40, may have a higher risk of developing dementia than those without primary insomnia. The Hisayama Study, a prospective cohort study was conducted to investigate the association between daily sleep duration and risk of dementia and death among community-dwelling Japanese subjects aged 60 and older without dementia [16]. Self-reported daily sleep duration was grouped into 5 categories depending upon duration of sleep; $<5.0,5.0-6.9,7.0-7.9,8.0-9.9, \geq 10.0$ hours. The association between daily sleep duration and risk of dementia and death was determined using a Cox proportional hazards models. After followup, 294 subjects developed dementia, and 282 died.

Age- and sex-adjusted incidence rates of dementia and allcause mortality were significantly greater in subjects with daily 
sleep duration of less than 5.0 hours and 10.0 hours and more than in those with daily sleep duration of 5.0 to 6.9 hours. These associations remained unchanged after adjustment for potential confounding factors $(<5.0$ hours: hazard ratio $(\mathrm{HR})=2.64,95 \%$ confidence interval $(\mathrm{CI})=1.38-5.05$ for dementia; $\mathrm{HR}=2.29,95 \%$ $\mathrm{CI}=1.15-4.56$ for death; $\geq 10.0$ hours: $\mathrm{HR}=2.23,95 \% \mathrm{CI}=1.42-3.49$ for dementia; $\mathrm{HR}=1.67,95 \% \mathrm{CI}=1.07-2.60$ for death). Similar U-shaped associations were observed for Alzheimer's disease and vascular dementia [16]. Interestingly, the risk of dementia and death, among subjects who used hypnotics with any sleep duration had a risk of dementia that was 1.66 times as great and a risk of death that was 1.83 times greater compared to those who did not use sleeping pills and had a daily sleep duration of 5.0 to 6.9 hours. It is possible that a short and long daily sleep duration and hypnotic use may be risk factors for dementia and death in Japanese elderly adults [16]. Behavioural risk factors appear to contribute in the pathogenesis of $\mathrm{AD}$ which is a neurodegenerative disorder characterized by significant disease burden. Sleeprelated pathological symptomatology often accompanies AD. The etiology and pathogenesis of disrupted circadian rhythm and $\mathrm{AD}$ share common factors, which also opens the perspective of viewing them as a mutually dependent process [78]. There is bi-directional relationship between these processes, indicating the pathophysiological links including neuro-inflammation, neurodegeneration, and circadian rhythm desynchronization. The underlying complexities linking AD and circadian rhythm disruption are based on interventions including melatonin. It is possible that novel anti-inflammatory treatments and those targeting metabolic alterations in $\mathrm{AD}$ might prove useful for normalizing a disrupted circadian rhythm. Treatment of circadian disruption may confer improvement in immunological, metabolic, and behavioral function in an affected individual.

Night shift work which also disrupts the circadian rhythm and predispose incident dementia has been examined in two populationbased cohorts from the Swedish Twin Registry (STR) [79]. The STR1973 sample included 13,283 participants born 1926-1943 who received a mailed questionnaire in 1973 that asked about status (ever/never) and duration (years) of shift work employment. The Screening Across the Lifespan Twin (SALT) sample included 41,199 participants born 1900-1958 who participated in a telephone interview in 1998-2002 that asked about night work status and duration. In genotyped subsamples ( $\mathrm{n}=2977$ in STR-1973; $\mathrm{n}=$ 10,366 in SALT), APOE $\varepsilon 4$ status was considered in models. A total of 983 (7.4\%) and 1979 (4.8\%) dementia cases were identified after a median of 41.2 and 14.1 years follow-up in the STR-1973 and SALT sample, respectively. Ever shift work (HR 1.36, 95\% CI 1.15-1.60) and night work (HR 1.12, 95\% CI 1.01-1.23) were associated with higher dementia incidence. Among APOE $\varepsilon 4$ carriers, individuals exposed to $\geq 20$ years of shift work and night work had increased dementia risk compared to day workers [79]. The results indicate that shift work, including night shift work, compared to non-shift jobs may increase the risk of dementia.

\section{Psychological Disorders and Dementia}

Although depression is one of the most important emotional problem that predisposes dementia, other emotional disorders such as anxiety and personality traits have also been demonstrat- ed to increase the risk or they may be associated with dementia $[80,81]$. The role of specific personality traits as risk factor of $\mathrm{AD}$ has been observed, whereas personality traits specifically related to AD needs clearance [80]. This meta-analysis included 10 primary studies and revealed that, when the personality was evaluated by informant-rated measures, AD patients had significantly higher levels of neuroticism, lower levels of openness, agreeableness, conscientiousness, and extraversion than HCs. However, evaluation of personality by self-rated measures, the results obtained from informants were confirmed for Neuroticism, Openness, and Extraversion but not for Agreeableness and Conscientiousness where $\mathrm{AD}$ patients and HCs achieved similar scores. It is possible that high neuroticism and low Openness and extraversion are distinctive personality traits significantly associated with a diagnosis of AD when evaluated both self-rated and informant-rated measures. This personality trait profile is similar to premorbid one, which contributes to development of $\mathrm{AD}$ over time. The findings indirectly support the idea of specific premorbid personality traits as harbingers of AD. The roles of both anxiety and depression as risk factors for frontotemporal dementia (FTD) and AD have been poorly examined [81]. This study included 84 patients with fronto-temporal dementia FTD and 556 patients with AD who were compared with 117 cognitively healthy $(\mathrm{CH})$, elderly individuals. Depression and anxiety were assessed with the Hospital Anxiety and Depression Scale (HADS). Significant The associations between anxiety and frontotemporal dementia and between depression and AD were highly significant. In patients having anxiety assessed via HADS, showed significant ( $p=0.017$ ) (odds ratio [OR]: 2.947, 95\% confidence interval increased risk of developing frontotemporal dementia [CI]: 1.209-7.158). A significantly increased risk of developing $\mathrm{AD}$ was also observed in patients who had reported depression on the HADS ( $\mathrm{p}=0.016$ ) (OR: 4.389, 95\% CI: 1.311-14.690). The findings indicate that anxiety and depression may play different roles as risk factors for frontotemporal dementia and $\mathrm{AD}$ [81].

\section{Buddha's Eight Fold Path and His Ten Commandments}

Since unhealthy behaviors and lifestyle factors are major determinants of dementia, it poses the possibility that modifications in the behaviors and lifestyle is the hallmark for prevention and treatment of dementia [71-88]. In the teaching of Buddhism, the Eight Fold Path determines the behavior of human beings [82,83]. The first path or step is to have either the right understanding or the correct view of life, which means knowing the truth of life meaning. More clearly, there is life after death so do not worry about future. The second path is right intention or aspiration, right thought, or the right to resolve, i.e., free your mind from evil deeds and evil feelings for others. The third step involves right speech: say nothing that hurts others which means do not speak truth that is painful for others. The fourth path involves the right action, or right conduct: means work for the good of others. The fifth step is right meaning for earning livelihood or self-respect that means our occupation should not be stressful to self and harmful to others and possibly involve some occupational physical activity. The sixth path is the right effort or resisting evil deeds as well as our efforts should not evolve evil thoughts for others. The seventh step involves the right concentration of mind: the practice of meditation or right understanding. Finally, the eighth path involves right mindfulness, 
or how to control one's thoughts in a way, to pay attention, so that others feel happy in discussing their problems and taking help from you. It is possible that Buddha was eating once a day in the evening which may be ninth path and eating balanced diet or right diet may the tenth path. Singh and co-workers have proposed that these suggestion on behaviors and lifestyles may be called as Ten Commandments of Buddha [82-86] \& (Figure 3).

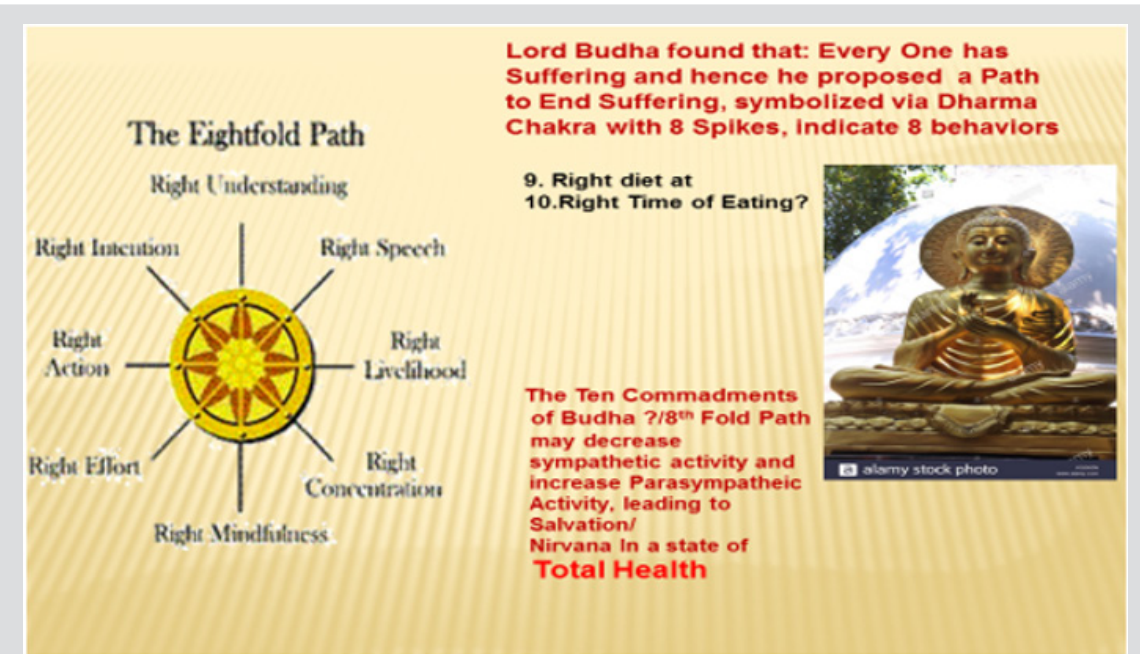

Figure 3: The Ten Commandments of Buddha for prevention of dementia. Buddha Eight Fold Path as 8 spikes on the wheel. Adding right time and right eating makes this package, The Ten Commandments of Buddha.

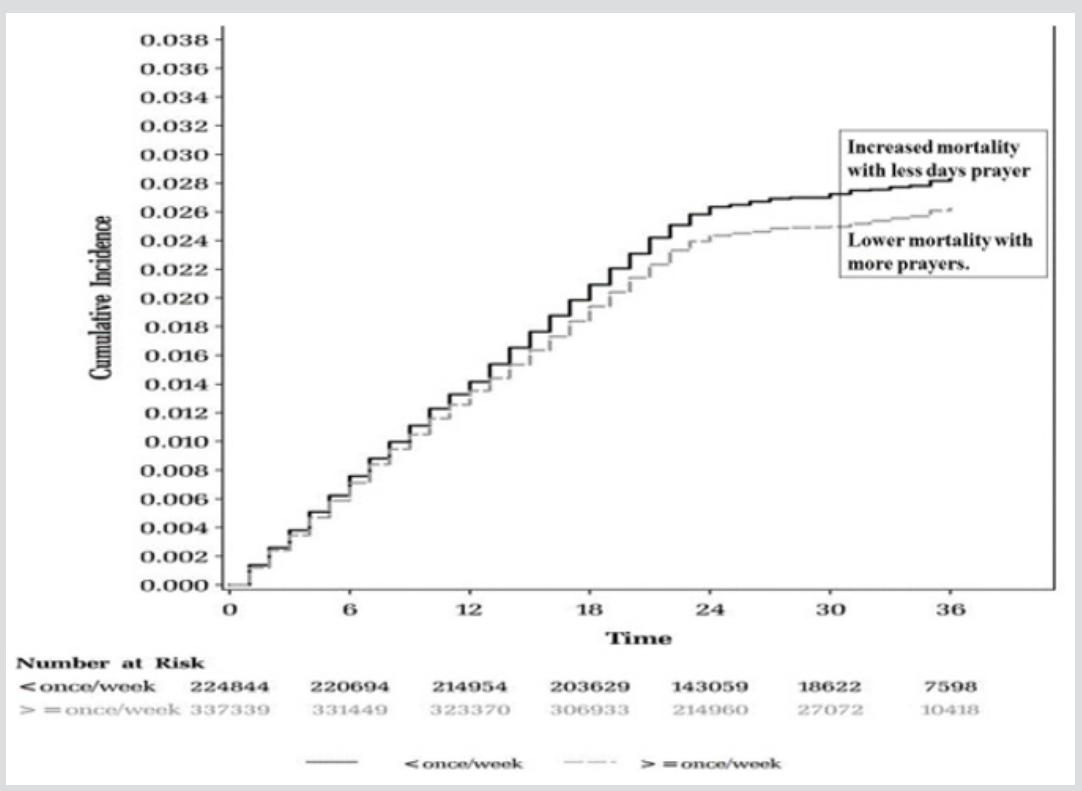

Figure 4: Time course graphs showing an association of increased mortality with fewer days of prayer compared to lower mortality associated with more days of prayer [85].

Regular physical activity may also improve behavior, but prayer appears to be more effective in altering one to one, behavior. In a previous study, the effects of direct contact in person-toperson prayer on depression, anxiety and positive emotions were examined during a follow-up of one year [86]. The study included 44 subjects who had undergone prayer intervention consisting of six weekly 1-hour prayer sessions conducted in an office setting. The post-prayer assessments done after one month and one year showed significantly less depression and anxiety, more optimism and greater levels of spiritual experience than did the pre-prayer measures ( $p<0.01$ in all cases). All patients with anxiety and depression maintained significant improvements for the duration of at least one year after the final prayer session. It appears that direct contact in person-to-person prayer may be a useful adjunct therapy as opposed to standard drug treatment for patients with depression and anxiety. In an epidemiological study involving 209 subjects, blood pressure and heart rate were recorded every 30 minutes, by ambulatory blood pressure monitored for 3-7 days. The results showed that a larger circadian amplitude of heart rate was associated with active prayer in Indians of Hindu religion [84]. In a prospective Nurses' Health Study (NHS), a cohort of 74,534 women who were free of CVDs and cancer at the start were recruited [85]; their religious service attendance was assessed by a self-reported questionnaire, which was collected initially in 1992, subsequently every four years. The investigators identified 13,537 deaths, including 2,721 dues to CVDs and 4,479 dues to 
cancer, during follow-up from 1996 until 2012. The results showed that attending religious service more than once per week was associated with $33 \%$ reduction in mortality, compared with women who had never attended religious services (HR=0.67, 95\%CI: $0.62-$ 0.71 , p-value for trend $<0.0001$ ). Comparing women who attended religious services more than once per week with those who never attended, the HR for cardiovascular mortality was 0.73 (0.62-0.85, $\mathrm{p}$ for trend $<0.0001)$; and cancer mortality was $0.79(0.70-0.89$, $\mathrm{p}$-value for trend $<0.0001)$. This study provided strong evidence that social support, depressive symptoms, smoking cessation, and optimism mediated the relationship between religious service attendance and reduced mortality. Interestingly, the findings of this study indicated that frequent religious service attendance may be associated with significantly lower risk of all causes of CVDs and cancer mortality [85]. Figure 4 illustrates the relationship between greater prayer intervention and lower mortality, whereas increased mortality occurred in the group with fewer prayer days.

It is known that apart from health behaviors, certain environmental factors such as space and weather can also influence neuronal function as well as mental and spiritual health which may influence behavior as well as physical and social health [86-90] In developing countries, higher income classes have a greater risk of hypertension, CAD and CVDs as well as type 2 diabetes mellitus which are risk factors of dementia $[82,84]$. In an epidemiological study, behavioral risk factors, sedentary life-style habits, excess salt intake and alcohol consumption, and other typical Western dietary habits were significantly more common among decedents belonging to higher social classes 1-3, compared to those within lower social classes 4 and 5 [82]. Lack of knowledge regarding healthcare education was significantly more common among decedents in lower income classes, who died earlier due to both communicable and non-communicable diseases, including longterm complications or end-organ failures. The results of this study as reviewed earlier, also showed that deaths associated with diabetes and CVDs were significantly more common among higher income classes 1-3, compared to lower income classes 4 and 5. However, deaths due to malignant and chronic lung diseases were not associated with social class (except the social class of women with breast cancer), but the total proportion of deaths due to NCDs was significantly greater among higher social classes 1-3, compared to lower social classes 4 and 5[82]. The findings showed for the first time that lack of health care education, (which is dependent on health behavior), despite better general education and income (prosperity), appears to be the major cause of deaths due to cardiovascular diseases and diabetes mellitus, especially among higher income classes 1-3 [82].

The results of several epidemiological studies indicate that social determinants of health and economic status, such as academic education and health education, occupation, household income, and availability of automobiles, are important indicators of lifestyle and food consumption patterns which can influence emotional and physical health $[82,97]$. These factors have similarity with paths suggested by Buddha and can influence our body systems and health $[82,83]$. Lack of many of these coronary protective factors have been found to be associated with acute coronary syndromes
[98]. These are important in the modern context because lack of health care education about behavioural risk factors can predispose to greater risk of CMDs as well as psychological disorders, anxiety, insomnia and depression despite greater prosperity [82,98-106]. Therefore, prosperity alone may not prevent NCDs and extend life span to serve the sustainable development goals of the UNO. These social markers, along with health care education, can significantly influence the levels of behavioral risk factors: namely religious service attendance, meditation and yoga, physical activity, dietary patterns, salt intake, alcohol consumption and tobacco use, which are important factors in the pathogenesis of NCDs [98-106]. Excessive indulgence in any of the health-related behaviors and unhealthy food habits may independently predispose to higher morbidity and mortality [82-88]. Mental and spiritual health are inter-related and are positively linked with healthy behavior, decreasing the risk of all diseases and increasing the quality of life for the individual [98-100]. In a meta-analysis involving 19 eligible cohort studies, 323,709 participants, 8,447 cases of myocardial infarction (MI) and coronary death were reported during followup ranging from 4 to 37 years [101]. The pooled adjusted Hazard Ratios for patients with depression (versus those without) were 1.22 (95\% CI: 1.13-1.32) for combined myocardial infarction (MI) and coronary death, 1.31 (95\% CI: 1.09-1.57) for MI alone (9 studies), and 1.36 (95\% CI: 1.14-1.63) for coronary death alone (8 studies). The increased risk of MI and coronary death associated with depression was consistent using modified inclusion criteria, across most subgroups, and after adjusting for possible publication bias. Depression was clearly associated with a significantly greater risk of MI and coronary artery disease (CAD) and death, thereby suggesting that prevention and treatment of depression may decrease the risk of CVDs. It is clear that depression is a risk factor of CVDs as well as dementia which can be controlled by regular practice of healthy behaviors $[82,83]$.

The Eight Fold Path of Lord Buddha shows the eight spikes indicating eight behaviors. Buddha also had a discipline in eating involving the right diet and at the right time of eating (evening), thus forming Ten Commandments of Buddha for total health [82]. A careful consideration of these behaviors indicates that if they are not followed properly, then the same may predispose to conflicts including personal as well as social conflicts, thereby causing adverse consequences in mental, social, spiritual, and physical health. A lack of adherence to Eight Fold Path of Buddha can predispose an individual to disturbance in social, mental and spiritual wellbeing, occasionally resulting in disturbed physical well-being of the body [82,83]. Thus, a continuing conflict between internal body environment and external social environment may result in chronic anxiety disorder, and cause excessive anxiety, depression, type A behavior and bipolar disorders as well as dementia, all leading to the distortion of body homeostasis and ultimately causing CMDs including obesity and diabetes mellitus that are in turn risk factors of dementia [98-102]. Mental dysfunctions and depression make the prevention of CVDs quite challenging, since due consideration has not been given to spiritual behavior modification. If they are not properly nurtured, then they can adversely affect our social and personal well-being, leading to undesirable consequences on 
mental health including dementia, characterized with symptoms summarized in Table 2.

\section{Practising Buddha's Eightfold Path Can Prevent Diseases}

A lack of adherence to Buddha's Eightfold Path can also predispose to disturbance in social, mental and spiritual well-being and occasionally resulting in disturbed physical well-being. Thus, a continuous interaction between internal environment and social environment may result in chronic anxiety disorders: anxiety, depression, type A behaviour leading to dementia. In turn, all of these can lead to CVDs, diabetes and other NCDs [98-102]. Figure 5 shows the possible beneficial effects of practicing Buddha's EightFold Path on the brain and other organs of the body in preventing chronic diseases including dementia. Effect of pranayama breathing patterns which is a type of yoga has been found to control behavior as well as naso-bronchial diseases [97]. A study by Fedacko et al. [98] showed that coronary protective factors and health behaviors are inversely associated with acute coronary syndromes (ACS), indicating that behavioral factors are important in the prevention of CVDs. There is much evidence that Western-type diets have adverse effects on the development of chronic anxiety disorders, whereas diets rich in Mediterranean foods may be more neuroprotective [99]. In a case-control study, 435 patients with ACS were compared with 495 age- and gender-matched control subjects. The incidence of depression ( $19.8 \%$ vs. $6.3 \%, \mathrm{P}<0.001)$ after the intake of Western-type foods was significantly more common among ACS cases compared to the control group [99]. The consumption of Indo-Mediterranean foods and blood nitrite concentrations were significantly lower among ACS patients as compared to the control group. After adjustment for age and BMI, depression was positively and strongly associated with ACS ( $\mathrm{P}<0.001)$, as shown by odds ratios and their $95 \%$ confidence intervals. Incidences of depression after intake of Western-type foods were significantly associated with ACS $(\mathrm{P}<0.001)$. Following the intake of IndoMediterranean food, the blood nitrite was inversely and weakly associated with ACS $(\mathrm{P}<0.02)$. A weaker positive association $(\mathrm{P}<0.02)$ of angiotensin converting enzyme (males: 0.57) with ACS was also found in this investigation. The results of this study also suggested that depression, Western-type food consumption, and high blood angiotensin converting enzyme were significant risk factors of ACS. Indo-Mediterranean food intake and blood nitrite showed beneficial effects on the risk of ACS [99]. Recently, the renin-angiotensin system has been shown to be a possible new target for the treatment of depression which possibly may also be a marker of dementia [100]. Association of circadian disruption of sleep and night shift work with risk of cardiovascular diseases has also been reported indicating that these morbidities may be in way of dementia [106].

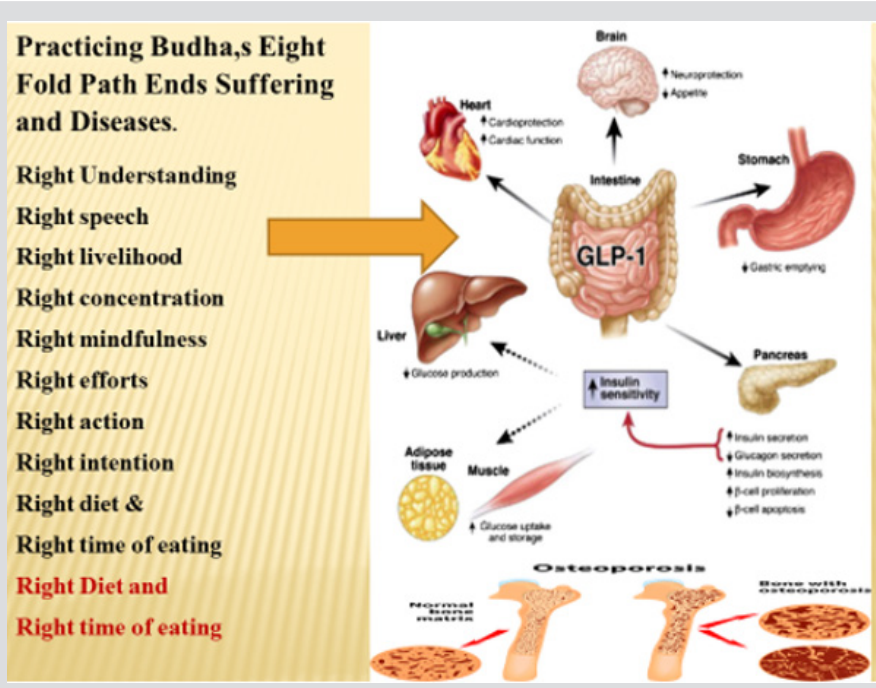

Figure 5: Possible beneficial effects of Buddha's Eight Fold Path on the brain and other body organs in the prevention of chronic diseases including dementia $[82,83])$.

Modifications in behavior may improve adherence to healthy behaviors like physical activity which is protective against CMDs and dementia [109]. In a cohort study, a total of 10,308 adults (33\% women) aged 35 to 55 years in 1985 were followed up until 2015 and in which BMI was assessed six times and 329 cases of dementia were recorded [25]. The changes in body mass index (BMI) for more than 28 years before dementia diagnosis were compared with changes in BMI in those free of dementia. The results revealed that obesity (BMI $\geq 30 \mathrm{~kg} / \mathrm{m} 2$ ) at age 50 years (hazard ratio $=1.93$; 1.35-2.75) but not at 60 or 70 years was associated with risk of dementia. Trajectories of BMI differed in those with dementia compared with all others $(\mathrm{P}<.0001)$ or to matched control subjects $(\mathrm{P}<.0001)$ such that BMI in dementia cases was higher from 28 years $(\mathrm{P}=.001)$ to 16 years $(\mathrm{P}=.05)$ and lower starting 8 years before diagnosis. The hypothesis that midlife obesity increases risk for dementia has been challenged by two sets of recent findings. The first using electronic patient records from 2 million adults showed lower rates of dementia in the obese and progressively decreasing risk with increasing obesity [107].

\section{Meditation, Mindfulness and Dementia}

Out of eight fold paths of Buddha, right concentration or meditation and mindfulness have been critically examined for their effects on health and diseases. Meditation which is hallmark of concentration is the most important component of yoga therapy. Yoga therapy also includes yoga postures, yoga prayer and yoga 
breathing as its major components which can influence health and behavior by their effects on autonomic nervous system [9196]. In a randomized controlled trial of transcendental meditation, the components of metabolic syndrome in subjects with coronary artery disease (CAD) were examined [96]. The results showed that practice of regular meditation can cause a significant decline in systolic blood pressure. Chronic hypertension is an important risk factor for heart failure and metabolic syndrome which are risk factors of dementia and which can be controlled by yoga therapy [96]. Meditation is known to improve sleep, decrease depression, reduce anxiety, down regulate inflammatory genes, upregulate immune system genes, improve insulin and glucose regulatory genes, and increase telomerase by $43 \%$; the largest ever recorded [108]. It also improves psycho-spiritual well-being or spiritual fitness, important for maintenance of cognitive function and prevention of $\mathrm{AD}$ [108]. In a clinical trial involving 81 subjects, treatment with kundalini yoga was associated with significant improvement in memory and depressive symptoms along with short- and long-term improvements in executive functioning and broader effects on depressed mood and resilience [110].

In another clinical trial among 100 subjects, short-term meditation $(n=27)$ practiced Raja Yoga meditation for a duration of six months to five years and long-term meditation $(n=73)$ practiced Raja Yoga meditation for more than five years [111]. Comparison between short term and long term meditation showed that the changes from baseline values (from premeditation to postmeditation at 15 and 30 minutes, in short term group were not statistically significant with those in the short term group $(\mathrm{P}>0.05)$. However, within group differences in long term group revealed that changes in the physiological variables, heart rate, blood pressures were statistically significant when compared between pre and post meditation both at 15 and 30 minutes. The study suggests that the long-term practice of Raja Yoga meditation improves basic cardio-respiratory functions due to shifting of the autonomic balance in favor of parasympathetic instead of sympathetic system. Another study of middle latency auditory evoked potential during Brahmakumaris Raja Yoga meditation revealed that there was a decrease in the peak latency of the Na wave (a negative wave between 14 and $19 \mathrm{msec}$.) during meditation [112]. Since the neural generator of this wave lies at the midbrain-thalamic level, from the results one can infer that the meditation reduces conduction time at this level. The regular practice of mental repetition of "OM" can cause significant changes in the middle latency auditory-evoked potentials, which indicate that it facilitates the neural activity at the mesencephalic or diencephalic levels [113]. The study comprised of 30 subjects aged 20 to 55 years, who had a minimum of 6 months experience in meditating "OM". Each subject was assessed in four sessions, i.e. two meditation and two control sessions. The two control sessions were:

a) Ekagrata, i.e. single-topic lecture on meditation and

b) Cancalata, i.e. non-targeted thinking.

The two meditation sessions were:

a) Dharana, i.e. focusing on the symbol "OM" and b) Dhyana, i.e. effortless single-thought state "OM". All four sessions were recorded on four different days and consisted of three states, i.e. pre, during and post.

The findings revealed that the wave $\mathrm{V}$ peak latency significantly increased in cancalata, ekagrata and dharana, but no change occurred during the Dhyana session [113]. It is possible that information transmission along the auditory pathway is delayed during cancalata, ekagrata and dharana, but there is no change during Dhyana. It may be said that auditory information transmission was delayed at the inferior collicular level as the wave $\mathrm{V}$ corresponds to the tectum.

There has been a surge of interest in the research on mindfulness as a psychological construct and as a modality of treatment. Currently, it is not clear how the teachings of Buddha and Western psychological aspects of mindfulness differ, and furthermore, how mindfulness can be integrated into modern medicine. There are cross-sectional studies and clinical trials on the associations between mindfulness and various indicators of psychological health. A few intervention studies on the effects of mindfulness-oriented interventions on psychological health, and laboratory-based experimental research on the immediate effects of mindfulness inductions on emotional and behavioral functioning have also been published [114,115]. Mindfulness may bring about various positive psychological effects, including emotional reactivity, greater subjective well-being, reduced psychological symptoms and improvement in regulation of behavior. Another review obtained a greater insight into the effects of MindfulnessBased Stress Reduction (MBSR) and Mindfulness-Based Cognitive Therapy (MBCT) on the mental health, involving 23 studies; 22 on the effects of MBSR and 1 on the effects of MBSR in combination with some aspects of MBCT. The results showed that the strongest outcomes were reduced levels of emotional exhaustion (a dimension of burnout), stress, psychological distress, depression, anxiety, and occupational stress. There were significant improvements in terms of mindfulness, personal accomplishment (a dimension of burnout), sleep quality, (occupational) self-compassion and relaxation, indicating that MBSR may help to improve psychological functioning $[114,115]$.

The present model of health has been considered the worst, because it gives no emphasis on spiritual behavior and pushing the world toward the slow-motion disaster in terms of total health and care for the patients [116]. Protective therapies to manage the patients with dementia and caregivers often focus on one or the other group, rather than the dyad. New strategies such as meditation, singing songs, and behavior with mindfulness are needed to train care giver to support the well-being of both caregiver and person with dementia [117-121]. In several studies, intervention with mindfulness training has shown to improve psychological well-being in both healthy subjects and in patients suffering from dementia [11-121]. The use of amyloid positron emission tomography (PET) associated with subsequent change in the management of patients with mild cognitive impairment (MCI) or dementia of uncertain etiology [121]. This study included 11409 participants with MCI or dementia of uncertain 
cause, patient management 90 days after amyloid PET changed (compared with the pre-PET plan) in $60.2 \%$ of patients with MCI and $63.5 \%$ of patients with dementia. It is possible that amyloid PET was associated with changes in the subsequent management of diagnostically challenging patients with cognitive disorders [121].

There is evidence that Kirtan Kriya (KK, singing religious songs),is an easy, cost effective meditation technique requiring only 12 minutes a day, which has been successfully employed to improve memory in studies of people with subjective cognitive decline, mild cognitive impairment, and highly stressed caregivers, all of whom are at increased risk for subsequent development of $\mathrm{AD}$ [119]. It also improves sleep, decrease depression, reduce anxiety, down regulate inflammatory genes, upregulate immune system genes, improve insulin and glucose regulatory genes, and increase telomerase by 43\%; the largest ever recorded [119]. KK also improves psycho-spiritual well-being or spiritual fitness, important for maintenance of cognitive function and prevention of AD. It is easy to learn and practice by aging individuals. specifically, along with other modalities such as dietary modification, physical exercise, mental stimulation, and socialization, which may be beneficial as part of an $\mathrm{AD}$ prevention program.

\section{Miscellaneous Factors Influencing Dementia}

Apart from abnormalities in psychological behavior, restricted feeding, either evening or morning, pollution, visualization of green land, have also been reported to influence various behavior patterns as recommended by Buddha's Eight Fold Path [83,123-125]. There is a common belief that a change in environment, from residing in a busy city to hills or sea shore or walking in green parks, can cause mental relaxation. Recently, a total of 110 clusters containing 541 vacant lots of land were enrolled in the trial and randomly allocated to the groups [30]. Of the 442 adults, a total of 342 (77.4\%) had follow-up data and were included in the analysis. Of these, 117 (34.2\%) received the greening intervention, 107 (31.3\%), the trash cleanup intervention, and 118 (34.5\%) no intervention. Intentionto-treat analysis of the greening intervention compared with no intervention demonstrated a significant decrease in participants who were feeling depressed $(\mathrm{P}=.03)$ and worthless $(\mathrm{P}=0.04)$, as well as a non-significant reduction in overall self-reported poor mental health $(\mathrm{P}=0.051)$. For subjects living in neighborhoods below the poverty line, the greening intervention demonstrated a significant decrease in feeling depressed $(P=0.007)$ [125]. Intention-to-treat analysis of those living near the trash cleanup intervention compared with no intervention showed no significant changes in self-reported poor mental health. These results indicate that change to living in an environment with green land can provide protection from depressed mood despite no prosperity. Overall, a review of literature has provided sufficient evidence that behavioral factors are important in the pathogenesis and prevention of CVDs. Eight Fold Path proposed by Buddha's recommendations may have a strong influence on behavioral factors and be a useful tool in the prevention of CMDs and dementia.

There is evidence that most chronic anxiety disorders as well as eating and sleep behaviors are associated with abnormal neurobiological mechanisms and neuronal dysfunctions [125-
130]. Recently Raj Yoga meditation has been found useful in the management of psychological disorders including dementia [131]. The functional neuroanatomy of depression suggests that the ventromedial and dorsolateral sectors of the prefrontal cortex are critical neural substrates with distinct alterations of neural circuits [130]. Functional Magnetic Resonance Imaging (MRI) has shown that major depression is normally presented with aberrant neural activity in the amygdala, hippocampus, striatum, prefrontal cortex, anterior cingulate cortex, and the thalamus. In turn, they can predict a subsequent reduction in the activation of prefrontal cortex in depression [130]. There is consistent evidence that fasting on alternate days and restricted feeding either in the morning or evening can influence energy metabolism regulated by the central circadian clock as well as peripheral clocks $[126,127]$. It has been announced by the UNO, that in order to achieve the Millennium Development Goal worldwide, childhood mortality has to be reduced by half and maternal mortality has to be reduced by $44 \%$. The above discussion makes clear that NCDs are not always associated with poverty and created inequity, but there is definite financial loss from NCD-related medical care because insurance coverage is not enough to meet the demand of management. There may be a high return for countries at all income levels, contributing to economic growth, due to investment in the prevention of NCDs.

\section{Mechanisms and Pathogenesis of Dementia}

Asia in general, India and China in particular have traditional approaches for diet and lifestyle changes for prevention of CMDs, including dementia [131]. It is possible to study the effects of traditional diets and lifestyle on mechanisms of dementia via neuroimaging. Functional magnetic resonance imaging (fMRI) and positron emission tomography are new technological advances which are used to study brain regions in majority of the brain diseases including dementia [128-132]. fMRI and fluorodeoxyglucose and amyloid PET are gaining traction in the clinical arena, but validity and cost-effectiveness remain to be established. Tau PET might offer new insights and be of great help in differential diagnosis and selection of patients for trials. However, the challenge is to diagnose preclinical Alzheimer's disease which is defined as biomarker evidence of Alzheimer's pathological changes in cognitively healthy subjects. Diabetes mellitus due to its slow grade inflammation, is the major risk factor of dementia which may be associated with white matter hypersensitivity (WMH) indicating deterioration of cognitive function and impairment in daily living. In a sample of 178 elderly patients with diabetes, there was a significant association between WMH volumes and Mini Mental State Examination (MMSE) scores ( $p=0.039)$ and between WMH and daily activity status [22]. A significant relation of large WMH volumes with a high glycoalbumin/glycohemoglobin ratio was also observed. Large WMH volumes were also found to be associated with a low body mass index, low blood pressure but not with $\mathrm{Hb} 1 \mathrm{c}$ [22]. Multiple regression analysis showed that high GA/HbA1c, which reflects high glucose variability, was a significant determining factor for large WMH volumes.

Obesity and hypertension are also risk factors of dementia which manifests particularly after 60 years of age which can produce changes in brain regions $[25,26]$. In one study, the relation of 
central obesity, hypertension, or depressive symptoms moderated the relationship between $\boldsymbol{\beta}$-amyloid $(A \beta)$ and longitudinal cognitive performance in late middle-aged adults enriched for AD) risk [26]. The study included 207 participants, aged 40-70 years with $73 \%$ having parental AD. The relationship between $A \beta$ and Verbal Learning \& Memory decline was moderated by hypertension $\left(\chi^{2}(1)\right.$ $=3.85, \mathrm{P}=.04)$ and obesity $\left(\chi^{2}(1)=6.12, \mathrm{P}=.01\right)$; those with both elevated $A \beta$ and the risk factor declined at faster rates than those with only elevated $A \beta$ or elevated risk factors. It is possible that hypertension and obesity can moderate the relationship between $\mathrm{A} \beta$ and cognitive decline. Apolipoprotein E (APOE) e4 gene is one of the major risk factors for $\mathrm{AD}$, therefore, adults who possess one copy of the APOE e4 gene are three times more likely to develop the disease than those without the gene. However, those with two copies are 8-12 times more likely to develop Alzheimer's. There are several types of dementia; Alzheimer's disease, dementia with Lewy bodies, frontotemporal dementia, vascular dementia, and mixed dementias. It is known that each of these dementing conditions has their unique pathologic signature, one common etiology shared among all these conditions is cerebrovascular dysfunction at some point during the disease process. The current findings and the important contributions of cerebrovascular, physiologic, and cellular alterations to cognitive impairment in these human dementias occur mostly due to diet and lifestyle changes. Smallvessel disease is the underlying neuro-pathologic hallmark of various dementias, but there may be controversial findings. The molecular mechanisms shared among all dementia types include hypoxia, oxidative stress, mitochondrial bioenergetics, neuroinflammation, neurodegeneration, and blood-brain barrier permeability responsible for aetiology and progression of disease.

\section{Diet and Lifestyle Guidelines for Prevention of Dementia}

Of the several guidelines that are proposed for prevention of dementia, the proposal by Bredson appears to be interesting [133-138]. He proposed 3 major risk factors for Alzheimer's; inflammation, nutrient deficiency, and accumulation of toxic substances [134]. Diabetes is an additional condition which is associated with a micro-inflammation and leaky gut which can rapidly promote Alzheimer's disease. These guidelines only provide a broad framework for assessment, management and follow-up of older people with dementia. While most of the recommendations are evidence based, these guidelines should not be considered as a substitute of professional knowledge and clinical judgment. The recommendations made as part of these guidelines should be tailored to address the clinical needs of the individual patient and the treatment setting. American Family Physicians Guidelines give greater emphasis on neuro-psycho- logical evaluation to identify the onset and type of mild cognitive impairment and dementia so that early intervention can occur [137]. Such evaluation can be useful in predicting the degree of driving risk and in determining decision making capacity in persons with dementia. It can identify cognitive deficits, predict functional outcomes, and monitor patient recovery after traumatic brain injury. Dementia is a highly prevalent acquired cognitive disorder that interferes with activities of daily living, relationships and quality of life [133]. Recognition and effective management strategies are necessary to provide comprehensive care for these patients and their families. High-quality clinical practice guidelines can improve the quality and consistency of care in all aspects of dementia diagnosis and management by clarifying interventions supported by sound evidence and by alerting clinicians to interventions without proven benefit. Clinical practice guidelines for the diagnosis of mild cognitive impairment (MCI) compared to dementia have been proposed by the Indian experts [135] (Table 3). These guidelines need modification by adding functional magnetic imaging(fMRI) or PET screening of brain. Moreover, no attempt is made to exclude the presence of depression in the existing guidelines [137].

Table 3: Mild cognitive impairment verses dementia (modified from reference 135).

\begin{tabular}{|c|c|c|}
\hline & $\begin{array}{l}\text { Mild cognitive impairment } \\
\text { (MCI) }\end{array}$ & Dementia \\
\hline 1 & $\begin{array}{l}\text { No significant impairment of } \\
\text { daily living. }\end{array}$ & $\begin{array}{l}\text { Severe interference in daily } \\
\text { living activities. }\end{array}$ \\
\hline 2. & $\begin{array}{l}\text { Impaired cognition in one or } \\
\text { more domains. }\end{array}$ & $\begin{array}{l}\text { Significant cognitive decline; } \\
\text { memory, speech, judgement, } \\
\text { visuospatial, behaviour. }\end{array}$ \\
\hline 3. & $\begin{array}{l}\text { Mild impairment in complex } \\
\text { aspects of daily activity. }\end{array}$ & $\begin{array}{l}\text { Significant impairment in } \\
\text { cognition. }\end{array}$ \\
\hline & Clinical Features & Clinical Features \\
\hline 4. & $\begin{array}{l}\text { Difficulty in doing more than } \\
\text { one task. }\end{array}$ & $\begin{array}{l}\text { Language, articulation and } \\
\text { personality problems. }\end{array}$ \\
\hline 5. & $\begin{array}{l}\text { Difficulty in solving complex } \\
\text { problems. }\end{array}$ & $\begin{array}{c}\text { Severe memory loss, } \\
\text { visuospatial dysfunction. }\end{array}$ \\
\hline 6 & $\begin{array}{l}\text { MCI may represent a } \\
\text { prodromal state of dementia, } \\
\text { but all cases do not develop } \\
\text { dementia. }\end{array}$ & Progressive cognitive decline. \\
\hline 7. & Depression should be excluded. & $\begin{array}{c}\text { Depressive symptoms may be a } \\
\text { part of dementia. }\end{array}$ \\
\hline 8. & $\begin{array}{c}\text { Brain is slightly active on } \\
\text { imaging. }\end{array}$ & $\begin{array}{l}\text { Significantly lower brain activity } \\
\text { on functional PET imaging. }\end{array}$ \\
\hline 9. & $\begin{array}{l}\text { Protective therapies may } \\
\text { reverse MCI. }\end{array}$ & $\begin{array}{c}\text { Moderate improvement by such } \\
\text { therapies. }\end{array}$ \\
\hline 10. & $\begin{array}{l}\text { Angiotensin converting } \\
\text { enzyme may increase. }\end{array}$ & $\begin{array}{c}\text { Angiotensin converting enzyme } \\
\text { high. }\end{array}$ \\
\hline
\end{tabular}

AGREE-II guidelines suggest that the management of dementia incorporates values, cultures and specific needs in care plans and interventions which includes encouragement for moderate exercise and recreational activities and participation in programs aimed at cognitive stimulation [133]. The driving ability should be evaluated at diagnosis and advise, and report, giving information at all stages of disease on available community and medical resources. These guidelines emphasise to re-evaluate disease progression in a comprehensive manner, including the option of using scales such as the MMSE. Drug management of cognitive aspects of dementia involves patient and family in decision making; such as discussion on adverse effects of drugs and benefits and adherence at every visit. In Alzheimer's dementia, consider cholinesterase inhibitors to treat mild-moderate dementia. Memantine may provide benefit in moderate-severe dementia. In vascular dementia, identify and treat vascular risk factors because acetylcholinesterase inhibitors are non-indicated in vascular dementia. However, acetylcholinesterase inhibitors can be considered for cognitive symptoms in Parkinson's disease-associated dementia. Alternative agents; herbal products 
and other pharmacotherapy including, but not limited to, gingko biloba, folic acid, vitamin B12, vitamin E, steroidal and nonsteroidal anti-inflammatory drugs, hormonal therapy and statin therapy are not recommended routinely for dementia management. Recommended therapies include music therapy and massage therapy, yoga postures, meditation and prayer, singing may be advised, apart from diet and lifestyle changes to prevent further progression of all the types of dementia (Table 4). Pharmacologic management of typical BPSD symptoms. Use medications sparingly only after non-pharmacologic approaches have failed, with awareness of side-effects. Advise patients and families on the risks and benefits prior to commencement of pharmacotherapy. Controversial therapies that cannot be recommended include aromatherapy and multisensory stimulation (also known as Snoezelen therapy). Atypical antipsychotics are preferred (over typical antipsychotics).

Table 4: Diet and lifestyle guidelines for prevention of memory dysfunction and dementia.

\begin{tabular}{|c|c|}
\hline $\begin{array}{c}\text { Mediterranean style diets and lifestyle } \\
\text { modification, }\end{array}$ & Quantity (g/day) \\
\hline Fruits, vegetables and nuts & 400 \\
\hline Whole grains; brown rice, millets & 400 \\
\hline Total fat; olive oil, mustard oil, rape seed oil & $30-50$ \\
\hline Probiotics; yogurt, curd & $100-300$ \\
\hline Chocolate & $50-100$ \\
\hline Fish (oily, protein and peptides) & $100-200$ \\
\hline Tea (green tea, more flavanol) & $2-10$ cups \\
\hline Moderate physical activity (minutes, twice per & $45-60$ \\
\hline Meditation, minutes/day & $20-30$ \\
\hline Yoga posture, minutes/day & $20-30$ \\
\hline Yoga breathing. Minutes/day & $20-30$ \\
\hline Yoga singing/verbalization, minutes & $12-20$ \\
\hline Prayer, minutes & $20-30$ \\
\hline Circadian restricted feeding (Most calories; \\
morning/evening) & $90 \%$ \\
\hline Caloric restriction, Calories/day & $1000-1500$ \\
\hline Intermittent fasting, (alternate day, biweekly of \\
weekly)
\end{tabular}

Low doses should be used and carefully up-titrated; taper as early as possible. There is lack of consensus for using benzodiazepines, anticonvulsants, mood stabilizers and SSRIs in dementia Evaluation and management of mood and other symptoms for comorbid depression. Non-pharmacologic therapy, such as cognitive behavioural therapy or psychotherapy and reminiscence therapy, is recommended first line therapy. In severe disease or after failed non-pharmacologic therapies, use an antidepressant; SSRIs are recommended, while tricyclic antidepressants are advised against. Cognitive behavioural therapy or psychotherapy is beneficial for caregivers facing psychological morbidity. Anticipate the financial impact of caring for a person with dementia in the home and discuss potential benefits available. Care givers should be involved in decision-making and advanced care planning; the use of advanced directives and identify surrogates for medical and legal decisionmaking. It is also proposed that the renin-angiotensin system could also be a possible new target for depression as well as dementia [100]. Because high concentrations of angiotensin converting enzyme has been observed among patients with MCI and dementia compared to healthy age and sex-controlled subjects. (Angiotensin converting enzyme (ACE) $(\mu \mathrm{m} / \mathrm{l})$, mean \pm standard deviation 104.5 \pm 11.5 vs $54.6 \pm 6.6$, personal communication, by RBS). This finding is important because treatment with ACE- inhibitors showed an improvement in cognition in patients with Alzheimer disease dementia but not in functionality (the Federal University of Sao Paulo presented at the 2018 Alzheimer's Association International Conference, July 22-26, 2018 in Chicago, Illinois).

In brief, in developed countries with high life expectancy, Alzheimer's disease is the most common form of dementia, accounting for about 60-80 percent of all cases. Since, in the United States alone, an estimated 5.4 million people have Alzheimer's disease, where western diet and lifestyle may be the cause of dementias, it is important to understand that these lifestyles need modification for prevention of dementia. Since apolipoprotein E (APOE) e4 gene is one of the biggest risk factors for Alzheimer's disease, therefore, adults who possess one copy of the APOE e4 gene are three-fold more likely to develop the disease than those without the gene. However, those with two copies are 8-12 times more likely to develop Alzheimer's. The results from the new studies suggest that the risk of dementia may be just as high for older adults exhibiting sedentary behaviour. Therefore, it is most important to advise diet and lifestyle changes and behavioural counselling for management of all types of dementia.

The guidelines for the management of dementia for Japanese were released in 2010 providing specific guidance for AD about clinical signs, image findings, biochemical markers, and approaches to management [14]. These guidelines are simply modifications of the Western guidelines indicating that there is a need to study the greater details of risk factors and protective factors among Japanese in the cross-sectional survey and cohort studies [17]. Drug therapies and non-pharmacotherapies to relieve cognitive symptoms have been advised, as were recommendations to achieve better patient care. Due to population aging and growing awareness of $\mathrm{AD}$ in Japan, health care expenditure and associated burden are expected to rise in the next one decade. There is a need to highlight the importance of early detection, diagnosis, and treatment of $\mathrm{AD}$ as strategies to minimize the impact of AD on society. In non-drug strategy, it is important to substitute global diets with functional foods; Indo-Mediterranean foods; whole grains (grams, red beans, kidney beans, millets, mustard oil and spices; fenugreek, turmeric, cumin and coriander etc) as well as typical Japanese foods (fish, soya beans, soy products, vegetables, whole rice ) for global prevention of dementia.

WHO in conjunction with Member States and other relevant stakeholders to improve the lives of people with dementia and their careers, while decreasing the impact of dementia on communities and countries? Areas for action include increasing prioritisation and awareness of dementia; reducing the risk of dementia; diagnosis, 
treatment and care; support for dementia carers; strengthening information systems for dementia; and research and innovation. In May 2017, the Seventieth World Health Assembly endorsed the global action plan on the public health response to dementia 2017 2025. This action plan includes seven strategic action areas and dementia risk reduction is one of them. Aligned with its mandate to strengthen the evidence base for dementia risk reduction, WHO has initiated the process of development of recommendations on risk reduction of cognitive decline and dementia.

\section{References}

1. (2017) WHO, Global action plan on the public health response to dementia 2017-2025? WHO, Geneva, USA, p: 52.

2. World Health Organization guidelines on risk reduction of cognitive decline and dementia, WHO, Geneva.

3. Catindig JA, Venketasubramanian N, Ikram MK, Chen C (2012) Epidemiology of dementia in Asia: insights on prevalence trends and novel risk factors. J Neurol Sci 321(1-2): 11-16.

4. (2014) Prina M and Alzheimer's Disease International (ADI), Alzheimers Australia, Published by Alzheimer's Disease International, London, UK.

5. Cadar D, Lassale C, Davies H (2018) Individual and area-based socioeconomic factors associated with dementia incidence in England: evidence from a 12-year follow-up in the English Longitudinal Study of Ageing. JAMA Psychiatry 75(7): 723-732.

6. Grant WB (2014) Trends in Diet and Alzheimer's Disease during the Nutrition Transition in Japan and Developing Countries. J Alzeimers Dis 38(3): 611-620.

7. Dodge HH, Buracchio TJ, Fisher GG (2012) Trends in the prevalence of dementia in Japan. Int J Alzheimers Dis 2012: 956354.

8. (2016) Alzheimer's Association. Alzheimer's disease facts and figures. Alzheimers Dement 12(4): 459-509.

9. Ikejima C, Ikeda M, Hashimoto M, Ogawa Y, Tanimukai S, et al. (2014) Multicenter population-based study on the prevalence of early onset dementia in Japan: vascular dementia as its prominent cause. Psychiatry Clin Neurosci 68(3): 216-224.

10. Tani Y, Suzuki N, Fujiwara T, Hanazato M, Kondo K (2019) Neighborhood food environment and dementia incidence: the Japan Gerontological Evaluation Study Cohort Survey. Am J Prev Med 56(3): 383-392.

11. Singh RB, Watanabe S, Mojto V, Takahashi T, Horuichi R, et al. (2019) Medical rice as a whole grain: A new technological advancement by Shaw Watanabe, for prevention of cardiometabolic diseases and dementia. Biomed J Sci \& Tech Res 14(4): 1-5.

12. Okamura H, Ishii S, Ishii T, Eboshida A (2013) Prevalence of dementia in Japan: A systematic Review. Dement Geriatr Cogn Disord 36(1-2): 111118.

13. Ohara T, Hata J, Yoshida D (2017) Trends in dementia prevalence, incidence, and survival rate in a Japanese community. Neurology 88(20): 1925-1932.

14. Montgomery W, Ueda K, Jorgensen M, Stathis S, Cheng Y, et al. (2018) Epidemiology, associated burden, and current clinical practice for the diagnosis and management of Alzheimer's disease in Japan. Clinico Economics Outcome research 10: 13-28.

15. Khan S, Singh RB, Wilkzynska A, Horiuchi R, Takahashi T (2019) Association of Western diet with risk of cognitive deficit and dementia in north India. Presented in the $19^{\text {th }}$ Scientific Meeting of the Japanese Society of Anti-Aging Medicine, Yokohama p. 14-16.

16. Ohara T, Honda T, Hata J, Yoshida D, Mukai N, et al. (2018) Association between daily sleep duration and risk of dementia and mortality in a Japanese community. J Am Geriatr Soc 66(10): 1911-1918.

17. Palmer K, Musicco M, Caltagirone C (2010) Are guidelines needed for the diagnosis and management of incipient Alzheimer's disease and mild cognitive impairment? International Journal of Alzheimer's Disease 2010: 417615.

18. Singh RB, Can Buddha, S Teachings (2019) Help in Health Promotion and Prevention of Dementia: The Ten Commandments of Buddha. Presented in the $19^{\text {th }}$ Scientific Meeting of the Japanese Society of Anti-Aging Medicine, Yokohama, June 14-16.

19. Ozawa M, Ninomiya T, Ohara T, Kazuhiro YD (2013) Dietary patterns and risk of dementia in an elderly Japanese population: the Hisayama Study the American Journal of Clinical Nutrition 97(5): 1076-1082

20. Karstens AJ, Tussing Humphreys L, Zhan L, Rajendran N, Catherine JC, et al. (2019) Associations of the Mediterranean diet with cognitive and neuroimaging phenotypes of dementia in healthy older adults. The American Journal of Clinical Nutrition 109(2): 361-368.

21. Tomata Y, Sugiyama K, Kaiho Y, Honkura K, Watanabe T, et al. (2016) Dietary patterns and incident dementia in elderly Japanese: The Ohsaki Cohort 2006 Study. The Journals of Gerontology: Series A 71(10): 13221328.

22. Tamura Y, Kimbara Y, Yamaoka T (2017) White matter hyperintensity in elderly patients with diabetes mellitus Is Associated with Cognitive Impairment, Functional Disability, and a High Glycoalbumin/ Glycohemoglobin Ratio. Frontiers in Aging Neuroscience 9: 220.

23. Li G, Wang LY, Shofer JB (2011) Temporal relationship between depression and dementia: findings from a large community-based 15year follow-up study. Arch Gen Psychiatry 68(9): 970-977.

24. Bae JB, Han JW, Kwak KP, Kim BJ, Kim SG, et al. (2019) Is dementia more fatal than previously estimated? A population-based prospective cohort study. Aging and Disease 10(1): 1-11.

25. Singh Manoux A, Dugravot A, Shipley M, Brunner EJ, Alexis Elbaz, et al. (2018) Obesity trajectories and risk of dementia: 28 years of follow-up in the Whitehall II Study. Alzhiemers \& dementia 14(2): 178-185.

26. Clark LR, Koscik RL, Allison SL et al. (2019) Hypertension and obesity moderate the relationship between $\beta$-amyloid and cognitive decline in midlife. Alzheimers \& dementia 15(3): 418-428.

27. Najar J, Östling S, Gudmundsson P, Sundh V, Johansson L, et al. (2019) Physical activity and dementia. Neurology 92(12): e1322-e1330.

28. LaCroix AZ, Bellettiere J, Rillamas Sun E, et al. (2019) Association of light physical activity measured by accelerometry and incidence of coronary heart disease and cardiovascular disease in older women. JAMANetw Open 2(3): e190419.

29. Singh RB, Rastogi SS, Verma, R Laxmi, B Singh R (1992) Randomized, controlled trial of cardio protective diet in patients with acute myocardial infarction: results of one year follow up. BMJ 304(6833): 1015-1019.

30. De Lorgeril M, Renaud S, Mamelle N, Salen P, Martin JL, et al. (1994) Mediterranean alpha-linolenic acid-rich diet in secondary prevention of coronary heart disease. Lancet 343(8911): 1454-1459.

31. Singh RB, Dubnov G, Niaz MA, Ghosh S, Singh R, et al. (2002) Effect of an Indo-Mediterranean diet on progression of coronary disease in high risk patients: a randomized single blind trial. Lancet 360 (9344): 1455-1461.

32. Esposito K, Marfella R, Ciotola M, DiPalo C, Giugliano G, et al. (2004) Effect of a Mediterranean-style diet on endothelial dysfunction and markers of vascular inflammation in the metabolic syndrome: a randomized trial. JAMA 292(12): 1440-1446.

33. Petersson SD, Philippou E (2016) Mediterranean diet, cognitive function, and dementia: A systematic review of the evidence. Adv Nutr 7(5): 889904.

34. Aridi YS, Walker JL, Wright ORL (2017) The Association between the Mediterranean dietary Pattern and cognitive health: A Systematic Review. Nutrients 9(7)

35. Martínez Lapiscina EH, Clavero P, Toledo E, Estruch R, Salas Salvadó J et al. (2013) Mediterranean diet improves cognition: the PREDIMEDNAVARRA randomised trial. J Neurol Neurosurg Psychiatry 84(12):13181325 
36. Bakoyiannis O, Daskalopoulou A, Pergialiotis V, Perrea D (2019) Phytochemicals and cognitive health: Are flavonoids doing the trick. Biomedicine \& Pharmacotherapy 109: 1488-1497.

37. Morris MC (2016) Nutrition and risk of dementia: overview and methodological issues. Ann N Y Acad Sci 1367(1): 31-37.

38. Mamiya T, Ukai M, Morikawa K, Kise M (2013) Intake of food pellets containing pre-germinated brown rice alleviates cognitive deficits caused by $\beta$-amyloid peptide25-35 in mice: Implication of lipid peroxidation. J Rice Res 1:116.

39. Reichelt AC, Stoeckel LE, Reagan LP, Winstanley CA, Page KA (2018) Prospective associations between single foods, Alzheimer's dementia and memory decline in the elderly. Physiology \& behavior 192: 118-126.

40. Morris MC, Tangney CC, Wang Y (2015) MIND diet slows cognitive decline with aging. Alzheimers Dement 11(9): 1015-1022.

41. Pistollato F, Iglesias RC, Ruiz R, Aparicio S, Crespo J, et al. (2018) Nutritional patterns associated with the maintenance of neurocognitive functions and the risk of dementia and Alzheimer's disease: A focus on human studies. Pharmacol Res 131: 32-43.

42. Solfrizzi V, Panza F, Frisardi V, Seripa D, Logroscino G, et al. (2011) Diet and Alzheimer's disease risk factors or prevention: The current evidence. Expert Rev. Neurother 11(5): 677-708.

43. Parletta N, Milte CM, Meyer BJ (2013) Nutritional modulation of cognitive function and mental health. J Nutr Biochem 24(5): 725-743.

44. Mi W, Van Wijk N, Cansev M, Sijben JW, Kamphuis PJ (2013) Nutritional approaches in the risk reduction and management of Alzheimer's disease. Nutrition 29(9): 1080-1089.

45. Swaminathan A, Jicha GA (2014) Nutrition and prevention of Alzheimer's dementia. Front. Aging Neurosci 6: 282.

46. Otaegui Arrazola A, Amiano P, Elbusto A, Urdaneta E, Martínez Lage P (2014) Diet, cognition, and Alzheimer's disease: Food for thought. Eur J Nutr 53(1): 1-23.

47. Jacobs DR, Steffen LM (2003) Nutrients, foods, and dietary patterns as exposures in research: A framework for food synergy. Am J Clin Nutr 78(3): 508-513.

48. Jacobs DR, Tapsell LC (2007) Food, not nutrients, is the fundamental unit in nutrition. Nutr Rev 65(10): 439-450.

49. Cederholm T (2017) Fish consumption and omega-3 fatty acid supplementation for prevention or treatment of cognitive decline dementia or Alzheimer's disease in older adults-Any news? Curr Opin Clin Nutr Metab Care 20(2): 104-109.

50. Arntzen KA, Schirmer H, Wilsgaard T, Mathiesen EB (2010) Moderate wine consumption is associated with better cognitive test results: A 7 year follow up of 5033 subjects in the Tromso Study. Acta Neurol Scand 190: 23-29

51. Berr C, Portet F, Carriere I, Akbaraly TN, Feart C, et al. (2009) Olive oil and cognition: Results from the three-city study. Dement Geriatr. Cogn. Disord 28(4): 357-364.

52. Loef M, Walach H (2012) Fruit, vegetables and prevention of cognitive decline or dementia: A systematic review of cohort studies. J Nutr Health Aging 16(7): 626-630.

53. Liu QP, Wu YF, Cheng HY, Xia T, Ding H et al. (2016) Habitual coffee consumption and risk of cognitive decline/dementia: A systematic review and meta-analysis of prospective cohort studies. Nutrition 32(6): 628-636.

54. Mandel SA, Youdim MB (2012) In the rush for green gold: Can green tea delay age-progressive brain neurodegeneration? Recent Pat. CNS Drug Discov 7(3): 205-217.

55. Lim HJ, Shim SB, Jee SW, Lee SH, Lim CJ, et al. (2013) Green tea catechin leads to global improvement among Alzheimer's disease-related phenotypes in NSE/hAPP-C105 Tg mice. J Nutr Biochem 24(7): 13021313.
56. Hu N, Yu JT, Tan L, Wang YL, Sun L, et al. (2013) Nutrition and the risk of Alzheimer's disease. Biomed Res Int 524820

57. Watanabe S, Endo K, Nakajou M, Takei N, Beppu S (2018) Low protein rice: medical Rice for chronic kidney Disease. In: RB Singh, Toru Takahashi, RR Watson. Role of Functional Food in Global Health, Elsevier, USA

58. Watanabe S, Hirakawa A, Nishijima C, Ohtsubo K, Nakamura K, et al. (2016) Food as medicine: the new concept of "medical rice". Adv Food Technol Nutr Sci Open J 2(2): 38-50.

59. Watanabe S (2018) Population-based strategy for preventing diabetes and its complications. Diabetes Res Open J 4(1): 1-4.

60. Okuda M, Fujita Y, Katsube T (2018) Highly water pressurized brown rice improves cognitive dysfunction in senescence-accelerated mouse prone 8 and reduces amyloid beta in the brain. BMC Complement Altern Med 18(1): 110.

61. Hamer M, Stamatakis E (2014) Prospective study of sedentary behavior risk of depression, and cognitive impairment. Med Sci Sports Exerc 46(4): 718-723.

62. Magnon V, Vallet GT, Auxiette C (2018) Sedentary Behavior at Work and Cognitive Functioning: A Systematic Review. Front Public Health 6:239.

63. Hartman YAW, Karssemeijer EGA, Van Diepen LAM, Thijssen DHJ (2018) Dementia Patients Are More Sedentary and Less Physically Active than Age- and Sex-Matched Cognitively Healthy Older Adults. Dement Geriatr Cogn Disord 46(1-2): 81-89.

64. Wheeler MJ, Dempsey PC, Grace MS (2017) Sedentary behavior as a risk factor for cognitive decline? A focus on the influence of glycemic control in brain health. Alzeimers \& dementia 3(3): 291-300.

65. Falck RS, Davis JC, Liu Ambrose T (2017) What is the association between sedentary behaviour and cognitive function? A systematic review. Br J Sports Med 51(10): 800-811.

66. Groot C, Hooghiemstra A, Raijmakers P, Van Berckel B, Scheltens P, et al (2016) The effect of physical activity on cognitive function in patients with dementia: a meta-analysis of randomized control trials. Ageing Res Rev 25: 13-23.

67. Sarah SE, Sheehan B, Atherton N, Nichols V (2018) Dementia and physical activity (DAPA) trial of moderate to high intensity exercise training for people with dementia: randomised controlled trial BMJ 361.

68. Bellettiere J, LaMonte MJ, Evenson KR, Rillamas Sun E (2019) Sedentary behavior and Cardiovascular Disease in older women; The OPACH Study. Circulation 139(8): 1036-1046.

69. Ekelund U, Steene Johannessen J, Brown WJ, Fagerland MW, Owen N et al. (2016) Does physical activity attenuate, or even eliminate, the detrimental association of sitting time with mortality? A harmonised meta-analysis of data from more than 1 million men and women. Lancet 388: 1302-1310.

70. Scheltens P, Blennow K, Breteler MM, de Strooper B, Frisoni GB, et al. (2016) Alzheimer's disease. Lancet. 388(10043): 505-517.

71. Yoshida J, Eguchi E, Nagaoka K, Ito T, Ogino K (2018) Association of night eating habits with metabolic syndrome and its components: a longitudinal study. BMC Public Health 18(1):1366

72. Floel A, Witte VA (2015) Impact of caloric restriction and caloric restriction-mimetics on brain structure and function in older adults and patients with mild cognitive impairment. Alzheemers \& Dementia 11(Supple 7): 303

73. Dhurandhar EJ, Allison DE, van Groen T, Kadish I (2013) Hunger in the absence of caloric Restriction improves cognition and attenuates Alzheimer's Disease pathology in a mouse model. Emily J PLOS 8(4): e60437.

74. Martin B, Mattson MP, Maudsley S (2006) Caloric restriction and intermittent fasting: two potential diets for successful brain aging. Ageing Res Rev 5(3): 332-353. 
75. Kim YH, Lee JH, Yeung JL (2019) Thermogenesis-independent metabolic benefits conferred by isocaloric intermittent fasting in ob/ob mice. Sci Rep 9(1): 2479

76. Escobar KA, Cole NH, Mermier CM, VanDusseldorp TA (2018) Autophagy and aging: maintaining the proteome through exercise and caloric restriction. Aging Cell 18(1): e12876.

77. Hung CM, Li YC, Chen HJ (2018) Risk of dementia in patients with primary insomnia: a nationwide population-based case-control study. BMC Psychiatry 18(1):38.

78. Homolak J, Mudrovčić M, Vukić B, Toljan K (2018) Circadian rhythm and Alzheimer's Disease. Med Sci (Basel) 6(3): 52

79. Bokenberger K, Sjölander A, Dahl Aslan AK, Karlsson IK, Åkerstedt T, et al. (2018) Shift work and risk of incident dementia: a study of two population-based cohorts. Eur J Epidemiol 33(10): 977-987.

80. Alfonsina D Iorio, Federica Garramone, Fausta Piscopo, Chiara Baiano, Simona Raimo, et al. (2018) Meta-Analysis of Personality Traits in Alzheimer's Disease: A Comparison with Healthy Subjects. J Alzheimers Dis 62(2): 773-787

81. Rasmussen H, Rosness TA, Bosnes O, Salvesen $\varnothing$, Knutli M, et al (2018) Anxiety and depression as risk factors in frontotemporal dementia and Alzheimer's Disease: The HUNT Study. Dement Geriatr Cogn Disord Extra 8: 414-425

82. Singh RB, Mojto V, Fedacko J, Buttar HS (2019) Practising the Eight-Fold Paths of Buddha could modify unhealthy behaviors and reduce noncommunicable diseases, to advance sustainable developmental goals of the united nations: a mini review. World Heart J11(1).

83. History, Philosophy and Teachings of Buddhism.

84. Singh RB, Cornelissen G, Kumar A, Bathina S, Halberg F (2009) Larger circadian amplitude of heart rate associated with active prayer in Hindu Indians in Asia. World Heart J 1: 219-222.

85. Li S, Stampfer MJ, Williams DR, Tyler J, Vander Weele TJ (2016) Association of religious service attendance with mortality among women. JAMA Intern Med 176 (6): 777-785.

86. Boelens PA, Reeves RR, Replogle WH, Koenig HG (2012) The effect of prayer on depression and anxiety: Maintenance of positive influence one year after prayer intervention. Int J Psychiatry Med 43(1): 85-98.

87. Singh RB, Bjorklund G, Shastun S, Cornelissen G, Elkilany GN, et al. (2016) Mental and spritual health and the heart: a viewpoint. World Heart J 8 (3): 233-238.

88. Singh S, Singh G, Kartikey K, Singh RB (2009) Effect of pranayama breathing patterns on naso-bronchial diseases: The power of breath. In Handbook of Pulmonary Medicine, Nova Science Publishers NY p. 1-9.

89. Halberg F, Cornelissen G, Sothern RB, Czaplicki J, Schwartzkopff O (2010) Thirty-five-year climatic cycle in heliogeophysics, psycho- physiology, military politics, and economics. Izv Atmos Ocean Phy 46(7): 844-864.

90. Cornelissen G, Halberg F, Breus T, Syutkina EV, Baevsky R, et al. (2002) Non-photic solar associations of heart rate variability and myocardial infarction. J Atmos Solar-Terr Phys 64(5-6): 707-720.

91. Singh RB, Singh S, Fedacko J, Pella D, De Meester F (2009) Pranayam yoga breathing practices modulate the mind-body connection. Int J Disability Human Dev 2: 141-153.

92. Borovikova LV, Ivanova S, Zhang M, Huan Yang H, Botchkina GI, et al (2000) Vagus nerve stimulation attenuates the systemic inflammatory response to endotoxin. Nature 405: 458-462.

93. Bernardi I, Gabutti A, Porta C, Spicuzza I (2001) Slow breathing reduces chemoreflex response to hypoxia and hyercapnia and increases baroreflex sensitivity. J Hypertens 19(12): 2221-2229.

94. Bernardi I, Wdowczyc Szulc J, Valenti C, Castoldi S, Passino C, et al. (2000) Effects of controlled breathing, mental activity and mental stress either with or without verbalization on heart rate variability. J Am Coll Cardiol 35(6): 1462-1469.
95. Rogowski O, Shapira I, Shirom A, Melamed S, Toker S, et al. (2007) Heart rate and micro-inflammation in men: a relevant atherothrombotic link. Heart 93(8): 940-944

96. Paul Labrador M, Polk D, Dwyer JH, Velasquez I, Nidich S, et al. (2006) Effects of a randomized controlled trial of transcendental meditation on components of the metabolic syndrome in subjects with coronary heart disease. Arch Intern Med 166(11): 1218-1224.

97. Singh RB, Verma SP, Niaz MA (1999) Social class and coronary artery disease in India. Lancet 353: 154

98. Fedacko J, Singh RB, Niaz MA, Bharadwaj K, Verma N, et al. (2016) Association of coronary protective factors among patients with acute coronary syndromes. J Cardiol Therapy 4(5): 671-677.

99. Singh RB, Fedacko J, Niaz MA, Hristova K, Elkilany G, et al. (2018) Association of diet and depression as risk factors among patients with acute coronary syndromes. World Heart J 10 (2): 127-142.

100. Vian J, Pereira C, Chavarria V, Köhler C, Stubbs B, et al. (2017) The renin-angiotensin system: a possible new target for depression. BMC Medicine 15(1): 144

101. Wu Q, Kling JM (2016) Depression and the risk of myocardial infarction and coronary death: A meta-analysis of prospective cohort studies. Xie W, ed. Medicine 95 (6): e2815.

102. Singh RB, Wilczynska A, Shastun S, Saboo B, Maheshwari A, et al. (2017) Association of chrono- physiological and psychological risk factors among patients with acute coronary syndromes. World Heart J(2): 123-134

103. Singh RB, Cornelissen G, Shastun S, Fedacko J (2017) Atherosclerosis: A disease of the brain. World Heart J 9: 99-106.

104. Van Dooren FEP, Nefs G, Schram MT, Verhey FR, Denollet J, et al. (2013) Depression and risk of mortality in people with diabetes mellitus: A systematic review and meta-Analysis. PLoS ONE 8 (3): e57058.

105. Singh RB, Anjum B, Garg R, Verma NS, Singh R, et al. (2012) Association of circadian disruption of sleep and night shift work with risk of cardiovascular diseases. World Heart J 4: 23-32.

106. Li L, Wu C, Gan Y, Qu X, Lu Z (2016) Insomnia and the risk of depression: a meta-analysis of prospective cohort studies. BMC Psychiatry 16 (1): 375 .

107. Qizibash N, Gregson J, Johson ME, Pearce N (2015) BMI and risk of dementia in two million people over two decades: a retrospective cohort study. Lancet Diabetes Endocriol 3: 431-436.

108. Khalsa DS (2015) Stress, meditation, and Alzheimer's disease prevention: Where the Evidence Stands. J Alzheimers Dis 48(1): 1-12.

109. Balducci S, D Errico V, Haxhi J (2019) Effect of a Behavioral Intervention Strategy on Sustained Change in Physical Activity and Sedentary Behavior in Patients with Type 2 Diabetes: The IDES 2 Randomized Clinical Trial. JAMA 321(9): 880-890.

110. Eyre HA, Siddarth P, Acevedo B (2017) A randomized controlled trial of Kundalini yoga in mild cognitive impairment. Int Psychogeriatr 29(4): 557-567.

111. Neelam D Sukhsohale, Mrunal S Phatak (2012) Effect of short-term and long-term Brahma Kumaris Raja Yoga meditation on physiological variables. Indian Journal of Physiology and Pharmacology 56(4): 38892.

112. Telles S, Naveen KV (2004) Changes in middle latency auditory evoked potentials during meditation. Psychological Reports 94(2): 398-400.

113. Kumar S, Nagendra HR, Naveen KV, Manjunath NK, Telles S (2010) Brainstem auditory-evoked potentials in two meditative mental states. Int J Yoga 3(2): 37-41.

114. Keng SL, Smoski MJ, Robins CJ (2011) Effects of mindfulness on psychological health: a review of empirical studies. Clin Psychol Rev 31(6): 1041-1056. 
115. Janssen M, Heerkens Y, Kuijer W, van der Heijden B, Engels J (2018) Effects of Mindfulness-Based Stress Reduction on employees' mental health: A systematic review. PLoS ONE 13(1): e0191332.

116. Takahashi T, Singh RB, Otsuka K, Watson RR, Wilson DW, et al. (2014) The 'West' has made the worst model of health and pushing the world to the slow moving disaster on total health. Editorial. World Heart J 6(3): 157-162.

117. Fjorback LO, Arendt M, Ornbøl E, Fink P, Walach H (2011) Mindfulnessbased stress reduction and mindfulness-based cognitive therapy: a systematic review of randomized controlled trials. Acta Psychiatr Scand 124(2): 102-119.

118. Khoury B, Sharma M, Rush SE, Fournier CJ (2015) Mindfulness-based stress reduction for healthy individuals: A meta-analysis. Psychosom Res 78(6): 519-528.

119. Hempel S, Taylor SL, Marshall NJ, Miake Lye IM, Beroes JM, et al. (2014) Evidence Map of Mindfulness. Washington, DC: Department of Veterans Affairs (US).

120. Khalsa DS (2015) Stress, Meditation, and Alzheimer's Disease Prevention: Where the Evidence Stands. J Alzheimers Dis 48(1): 1-12.

121. Rabinovici GD, Gatsonis C, Apgar C (2019) Association of amyloid positron emission tomography with subsequent change in clinical management among aedicare beneficiaries with mild cognitive impairment or dementia. JAMA 321(13): 1286-1294.

122. Berk L, Warmenhoven F, van Os J, van Boxtel M (2018) Mindfulness training for people with dementia and their caregivers: Rationale, current research, and future directions. Front Psychol 9: 982.

123. He Q Zhang P, Li G, Dai H, Shi J (2017) The association between insomnia symptoms and risk of cardio-cerebral vascular events: A meta-analysis of prospective cohort studies. Eur J Prev Cardiol 24 (10): 1071-1082

124. Wilczynska A, Singh RB, Fedacko J, Singhal S, Gupta N, et al. (2018) Validation of Type A behaviour questionnaire in relation to social class and coronary artery disease: The Indian Rating Scale for Type a Behavior. J Cardiol Therapy 5 (1): 707-712.

125. South EC, Hohl BC, Kondo MC, MacDonald JM, Branas CC (2018) Effect of greening vacant land on mental health of community-dwelling adults A cluster randomized trial. JAMA Network Open 1(3): e180298.

\section{ISSN: 2574-1241}

DOI: 10.26717/BJSTR.2019.17.003006

Shaw Watanabe. Biomed J Sci \& Tech Res

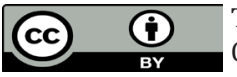

This work is licensed under Creative

Commons Attribution 4.0 License

Submission Link: https://biomedres.us/submit-manuscript.php
126. Singh RB, Takahashi T, Hristova K, Maheshwari A, Niaz MA, et al. (2016) Effects of circadian restricted feeding and low energy intake, on risk of cardiovascular disease and type 2 diabetes mellitus. World Heart J 8: 315-327.

127. Singh RB, Maheshwari A, Cornelissen G, Hadi NR, Mohammad BI, et al. (2015) Can circadian restriction of feeding modulate autonomic nervous system dysfunction and cardiometabolic risk? World Heart J 7: 31-42.

128. Seki K, Yoshida S, Jaiswal MK (2018) Molecular mechanism of noradrenaline during the stress-induced major depressive disorder Neural Regen Res 13(7): 1159-1169.

129. Patriquin MA, Mathew SJ (2017) The neurobiological mechanisms of generalized anxiety disorder and chronic stress. Chronic Stress (Thousand Oaks) p. 1.

130. Koenigs M, Grafman J (2009) The functional neuro-anatomy of depression: distinct roles for ventromedial and dorsolateral prefrontal cortex. Behav Brain Res 201(2): 239-243.

131. Rajoria K, Singh SK (2017) Therapeutic benefits of Raj Yoga. A review. Ind J Traditional Knowledge 16 (Supple):88-95

132. Raz L, Knoefel J, Bhaskar K (2016) The neuropathology and cerebrovascular mechanisms of dementia. J Cereb Blood Flow Metab 36(1): 172-186

133. Ngo J, Holroyd Leduc JM (2015) Systematic review of recent dementia practice guidelines. Age and Ageing 44(1): 25-33.

134. Bredesen D (2018) The end of Alzheimer's; The first programme to prevent and reverse the cognitive decline of dementia. 50(6): 476-477.

135. Shaji KS, Sivakumar PT, Rao GP, Paul N (2018) Clinical Practice Guidelines for management of dementia. Indian J Psychiatry 60(Suppl 3): S312-S328.

136. National Institute of Health and Care Excellence, Dementia Management.

137. Schroeder RW, Martin PK, Walling A (2019) Dementia, neuropsychological Evaluations in Adults. Am Fam Physician 99(2): 101-108

138. Press D, Alexander M (2017) Prevention of dementia. Uptodate.

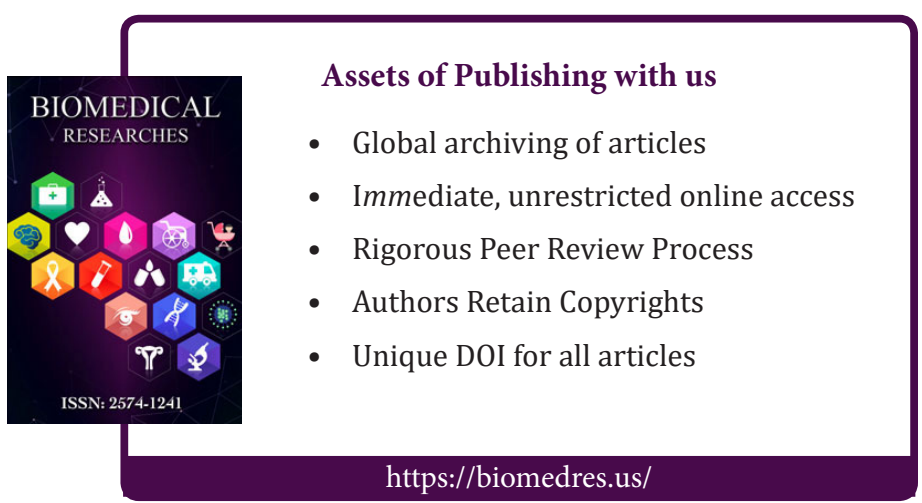

